\title{
JUEZ Y PARTE: SOBRE EL \\ CONOCIMIENTO PRIVADO DEL \\ JUEZ Y SU USO PARA FUNDAMENTAR \\ LA DECISIÓN JUDICIAL.
}

'La justicia es una cosa muy seria; pero precisamente por ello no es necesario, señor juez, que usted, desde su asiento, me frunza con fiereza el

entrecejo'.

(Piero Calamandrei)

Juan Sebastián Calderón B.

Felipe Gonzalo Jiménez M.

\section{Apartes de la sentencia}

\author{
República de Colombia \\ Rama Judicial \\ Tribunal Superior \\ Distrito Judicial de Bogotá \\ Sala penal \\ Magistrado ponente: Orlando Muñoz Neira \\ Radicación: 11001600004920070885701
}

Procedencia: Juzgado $23^{\circ}$ Penal Municipal de Conocimiento.

Acusados: JPVB

JGLF

HRM

Delito: Lesiones personales culposas

Motivo: Apelación sentencia condenatoria.

Decisión: Confirma

Aprobado: Acta No. 071 del 7 de julio de 2015

Fecha de lectura: 9 de julio de 2015. Hora: 11:00 a.m 


\begin{abstract}
Asunto
El propósito de esta providencia es decidir el recurso de apelación interpuesto por los abogados defensores contra la sentencia del 6 de mayo de 2015, por medio de la cual el Juzgado 23 Penal Municipal con función de conocimiento de esta ciudad capital, condenó a los médicos JPVB, JGLF y HRM, a la pena principal de diecinueve (19) meses y seis (6) días de prisión y multa de seis punto seiscientos sesenta y seis (6.666) salarios mínimos mensuales, al hallarlos penalmente responsables del delito de lesiones personales culposas.

El proyecto inicial, presentado por el magistrado Hermens Darío Lara, fue derrotado y por tanto la decisión aquí contenida corresponde al criterio de la sala mayoritaria.
\end{abstract}

\title{
1. Hechos
}

Hace ocho años, en el 2007, el niño DSMR, para entonces de tres años, sufrió dos accidentes en los cuales su testículo izquierdo resultó golpeado. Uno fue el 19 de julio. La madre del menor, NYRB, lo llevó a diversos centros médicos, hasta que el 23 de julio fue atendido en el Hospital San José por la pediatra NV, quien, de inmediato, ordenó una ecografía escrotal, y una revisión de esta por el urólogo AN, quien descartó que existiera una torsión testicular, y dispuso una nueva cita, al día siguiente en horas de la mañana.

El jueves 11 de octubre, de nuevo el infante DSMR se golpeó el mismo testículo izquierdo. Doña NY solicitó una cita prioritaria y la obtuvo en la Cruz Roja de la Avenida 68. El niño tenía inflamado el testículo. Allí la atendió la médica general JPVB, quien ordenó una ecografía y tras mirar los testículos del niño, le dio de alta, no sin antes recetarle Ibuprofeno, y sugerir una cita con pediatría. Doña NY llamó a Compensar, su EPS, y pidió la cita pediátrica que la doctora VB le había recomendado. Sin embargo, en Compensar no le dieron cita alguna, pues la doctora VB no había emitido orden escrita.

Ese jueves, el niño siguió empeorando y no paraba de quejarse. Entonces, la señora NY se acordó de que en el incidente de julio había recibido una muy buena atención en el Hospital San José, y partió allí con el padre del niño. Sin embargo, la médica que los había atendido en julio no estaba trabajando esa noche; en cambio, fueron recibidos por el pediatra de turno, JGFL. Este revisó al niño y observó la ecografía tomada en la mañana, pero fuera de hacer un examen físico, no ordenó ningún otro examen. Como la madre había escuchado, en el accidente de julio, el riesgo de la torsión testicular, le preguntó por ello al doctor FL, pero este le respondió: "Si usted es médico, ¿para qué me lo trae?". Dispuso entonces que el niño continuara con Ibuprofeno y le dio una cita para consulta externa de urología pediátrica, pero sin carácter prioritario.

La salud del niño no paraba de desmejorar. Entonces, la señora RB obtuvo, para la tarde del viernes 12 de octubre, una cita en una IPS de Compensar, ubicada en el barrio Villa Luz de esta ciudad capital. Para entonces, el testículo del niño, de lo inflamado que estaba, parecía una ciruela. La cita era a las dos de la tarde, y una hora después fue atendida por el pediatra HRM. Este lo revisó, pero igual no le ordenó examen alguno, sino que le cambio de medicamento: de Ibuprofeno a Naxopreno. Esto último, al parecer, es más fuerte contra el dolor. El médico RM, sin embargo, notó una afectación en el pecho del párvulo, y ordenó unas terapias respiratorias.

Al día siguiente, sábado 13 de octubre, doña NY llevó al niño a la terapia respiratoria a la Clínica San Rafael. En medio de la terapia, la madre rompió en llanto por el dolor testicular de su hijo; entonces, al ver el drama, la terapeuta contactó a la pediatra AXD, 
quien tras observar al menor dispuso intervenirlo quirúrgicamente de inmediato pues sospechaba una torsión testicular. La exploración quirúrgica confirmó sus sospechas: el testículo izquierdo se había torcido, mas para entonces ya era demasiado tarde: el testículo había muerto por falta de irrigación sanguínea.

\section{Sentencia apelada}

3.1. Mediante fallo proferido el 6 de mayo de 2015, el juzgado de conocimiento condenó a los tres acusados a la pena principal de diecinueve (19) meses y seis (6) días de prisión, multa equivalente a 6.666 salarios mínimos mensuales, e inhabilitación para el ejercicio de derechos y funciones públicas por el mismo término, y para el ejercicio de la profesión médica por seis (6) meses, al hallarlos penalmente responsables del delito de lesiones personales culposas.

En la misma, se concedió la suspensión de la ejecución de la pena por un periodo de prueba de dos (2) años.

3.2. Luego de hacer un recuento respecto de la actividad de práctica médica riesgosa y el riesgo permitido en ella, aseguró que el deber objetivo en esta profesión se circunscribe a la "observancia de los protocolos médicos que orientan la atención de un paciente de acuerdo a su estado de salud, que constituye la guía de una práctica médica adecuada y aconsejable, para el tratamiento de un enfermedad determinada"1.

Con fundamento en lo anterior, entró a valorar el peritaje rendido por la doctora LTP, para señalar que, si bien en este se asegura que existieron deficiencias en la atención médica recibida por el menor DSMR., lo cierto es que no cuenta con la fuerza probatoria suficiente para considerar demostrada la tipicidad de la conducta, por tres motivos principales: i) la falta de idoneidad de la perito al no ser uróloga o cirujano pediatra; ii) la referencia que hizo a una junta institucional sin dar mayores detalles al respecto; y iii) haberse sustentado en una consulta vía telefónica con un especialista, sin que le fuesen remitidos los soportes mínimos para emitir un concepto científico confiable.

3.3. Dicho esto, y luego de precisar que en Colombia no existe un protocolo oficial sobre atención de pacientes con diagnóstico de escroto agudo, informó que el despacho, tras realizar una ardua tarea académica, encontró un protocolo de abordaje diagnóstico del escroto agudo en niños y adolescentes, emitido por el Gobierno Federal de México y conocido con el código IMSS 229-10, documento en el cual se precisa que el tratamiento a este tipo de pacientes debe realizarse mediante atención quirúrgica inmediata.

Así las cosas, agregó, lo mínimo que se podía exigir a los procesados en su calidad de médicos tratantes, es que, una vez determinado el trauma testicular, se remitiese de inmediato a un especialista en urología o cirugía pediatra, quien a su vez debía adelantar la atención quirúrgica necesaria para establecer la condición real del menor, y así detectar la existencia de torsión testicular en lugar de la epididimitis inflamatoria que le fue finalmente diagnosticada.

Concluyó, entonces, que "existió por parte de los procesados una infracción al deber objetivo de cuidado, al desconocer que el diagnóstico de escroto agudo en un niño de tres años, constituye frente a la buena práctica médica una urgencia quirúrgica, lo que motivaba por sí solo la remisión inmediata al menor al cirujano pediatra o al urólogo"2 2 .

\footnotetext{
${ }^{1}$ Fl. 61 ibídem.

${ }^{2}$ Fl. 58 ibídem.
} 
3.4. En cuanto a los testigos de la defensa, quienes aseguran que la atención de los médicos aquí investigados fue correcta y acorde con los síntomas que presentaba el menor al momento de la consulta, consideró que los mismos no desvirtúan la responsabilidad penal de los implicados habida cuenta de que, tal y como se establece en el protocolo traído a colación por el juzgado, la atención de un diagnóstico de escroto agudo en niños, sin importar los síntomas que presente, siempre es de urgencia quirúrgica.

Inconforme con la decisión, los abogados de cada uno de los tres acusados, por separado, interpusieron recursos de apelación.

\section{$[\ldots]$}

\section{Consideraciones}

\subsection{Culpa médica en el ámbito penal}

5.1.1. La responsabilidad médica, en nuestro derecho, es de diferentes clases: la hay de tipo ético, que es definida por pares de los galenos a través del Tribunal de Ética Médica ${ }^{3}$; también puede darse una responsabilidad civil por daños, y la responsabilidad penal, sin perder de vista que, en el caso de entidades oficiales prestadoras de servicios de salud, también puede existir una responsabilidad de tipo contencioso-administrativo. A ello hay que sumar controles ejercidos por órganos territoriales de salud en materia de habilitación ${ }^{4}$, y posibilidades de vigilancia y control que sobre determinadas entidades de seguridad social en salud ejerce la Superintendencia Nacional de Salud ${ }^{5}$.

En otras palabras, ante un mal servicio de salud, no es la llamada jurisdicción penal la única llamada a regular el caso, y tal vez no sea la más eficiente a la hora de que la satisfacción de los derechos del paciente tenga plena vigencia. Así, para citar un solo ejemplo, en materia civil, los desarrollos doctrinales y jurisprudenciales permiten hoy la estructuración de responsabilidad objetiva.

La responsabilidad "objetiva" (Responsabilità Oggetiva, Responsabilité objective, Strict liability, Objektive Haftung, Gefährdunggshaftungg), por oposición a la "subjetiva" describe hipótesis de imputabilidad sin culpa, donde la culpabilidad carece de relevancia para estructurarla remitiéndose a factores objetivos como el riesgo o el peligro, la capacidad de asumir los costos de evitación o de reparar la lesión, fundándose en la situación del sujeto respecto de las cosas, su posición o relación con sus congéneres o el ejercicio de una actividad riesgosa o peligrosa permitida por su utilidad social, verbi gratia, la custodia de una cosa, la propiedad sobre ésta, el uso de un animal o el riesgo ${ }^{6}$.

5.1.2. Pero quien escoge el sendero penal como vía procesal para lograr la reparación de un daño médico, no puede aspirar, ni a un régimen de responsabilidad objetiva como en civil, ni mucho menos a uno donde probatoriamente la carga favorezca a la víctima. Todo lo contrario: el proceso comienza y avanza con una presunción de inocencia, que no significa otra cosa que, desde el punto de vista probatorio, el camino procesal inicia a favor de los acusados. Esto no significa que, de acreditarse la responsabilidad penal, la víctima quede

\footnotetext{
${ }^{3}$ Ley 23 de 1981.

${ }^{4}$ Ley 715 de 2001, art. 56 y decreto 1011 de 2006, entre otros.

${ }^{5}$ Ley 15 de 1989, y ley 1122 de 2007, entre otras.

${ }^{6}$ CSJ. Sala Civil. Ago. 24 / 09 MP Namén Vargas, e-1054.
} 
desprotegida, pero si aquella no se acredita con la suficiencia probatoria exigida (que es bien alta), el proceso penal, en términos reparativos, no ha prestado servicio alguno.

Esto hace que una responsabilidad médica de tipo penal no sea frecuente. La ley exige, a nivel de tipo subjetivo, para que la conducta sea culposa, que el daño que el paciente ha sufrido sea el resultado de un riesgo puesto por la acción u omisión del médico, cuando ese riesgo, en concreto, signifique una infracción al deber objetivo de cuidado de tal profesional, bien porque el resultado fue previsto pero con confianza en que se podía evitar, o bien porque no fue previsto muy a pesar de ser previsible.

Hablar de infracción al deber profesional del médico hace que, en materia penal, el juzgador deba evaluar el comportamiento del galeno en comparación con los estándares de la ciencia médica. Por eso, algunos utilizan la expresión latina "lex artis" "para referirse a un cierto sentido de apreciación sobre si la tarea ejecutada por un profesional es o no correcta o se ajusta o no a lo que debe hacerse." ${ }^{7}$ Los estudiosos del tema señalan que la lex artis es "la aplicación de las reglas generales médicas a casos iguales o parecidos o la actuación conforme a cuidado objetivamente debido." ${ }^{8}$

5.1.3. Y como lo usual es que los abogados (defensores, fiscales y jueces) no tengamos conocimientos médicos distintos a las nociones muy básicas de medicina legal vistas en algún semestre del pregrado o en un par de clases de una "especialización", lo que es de esperar es que en los procesos penales se presenten peritos o expertos, cuyas posturas científicas le han de servir al tercero imparcial para tomar una decisión. Siendo esta una característica obvia del proceso penal, no debe asustar la presencia de dictámenes y pareceres profesionales enfrentados, de modo que esta laya de procesos es bien distinta de aquella otra donde la prueba corre en contra del acusado de principio a fin.

5.1.4. Con todo, el juez penal debe tener en cuenta que, en este tipo de procesos, no es que se deba asistir a una especie de guerra de dictámenes periciales. En otras palabras, no se trata de que, entre los diferentes pareceres de peritos médicos, unos a favor y otros en contra de los médicos acusados, el juez tenga que ser algo así como un súper médico que determine el diagnóstico correcto. No. Lo que el juez debe determinar es, si con base en las pruebas practicadas, la acción u omisión del médico constituyó un riesgo, pero no cualquiera, sino un riesgo indebido, contrario a los deberes profesionales, el cual se concreta en un resultado por falta de previsión o por previsión unida a una infundada confianza de evitación.

Ahora bien; en la búsqueda de ese cometido hay que ser claros: el único conocimiento valedero no es el de los expertos. También el conocimiento del paciente, su vivencia, las peripecias por las que ha atravesado, sus dolencias, su camino hacia la recuperación, sus recaídas, etc. son un conocimiento, no experto, pero en ningún momento digno de ser omitido. El lenguaje de uno y otro conocimiento, de seguro será distinto, pero no por el hecho de ser muy técnico el uno, o muy vernáculo el otro, puede aquel prevalecer sobre este, o al revés.

\subsection{Las hipótesis enfrentadas en el caso concreto}

5.2.1. Con el anterior preámbulo, veamos las hipótesis que están enfrentadas en este asunto. La hipótesis de la fiscalía es simple pero contundente: según el ente acusador, el

\footnotetext{
${ }_{7}^{7}$ Valencia Pinzón, Giovanni. La lex artis. Aspectos de Responsabilidad. Revista Médico-Legal, 2001, Vol. 7.

${ }^{8}$ Ibídem.
} 
menor DSMR pasó, en menos de dos días, por manos de tres médicos (los acusados), y ninguno de ellos le ordenó exámenes que permitieran descubrir que lo que aquejaba el niño era una torsión testicular. Por ese desatino en el diagnóstico, el niño terminó perdiendo el testículo izquierdo.

La hipótesis de la defensa es más elaborada y está fincada en explicaciones técnicas que afirman que el diagnóstico que, en su momento, dieron cada uno de los tres médicos fue el correcto, al igual que el tratamiento ordenado. El juez de primera instancia, ante las críticas hechas al dictamen de medicina legal que le achaca la culpa a los acusados, optó por hallar un protocolo mexicano de tratamiento médico para casos de dolores testiculares, y con base en él presagió que los encausados profesionales no ordenaron la cirugía que corresponde en tales casos.

Los defensores, casi que al unísono, sostienen que con ello el juez aplicó un conocimiento particular. No lo cree así el tribunal. El juez decidió hacer una averiguación, que la ley no le prohíbe: explorar un conocimiento que no es secreto, que no está metido en catacumbas, que no es prohibido averiguar, sobre la manera correcta de abordar la enfermedad que aquejaba al niño. Distinto hubiera sido que el juez se hubiera ido, el mismo, con los dictámenes e historia clínica del caso, a consultar con profesionales que no concurrieron al juicio, para ver, cómo, en una condición superior, podía determinar cuál diagnóstico era el acertado.

Pero que alguien (un juez) que no es médico, que no es analfabeto, que tiene un honorable nivel de educación, quiera hacer las veces de autodidacta, y consulte literatura médica, no se convierte, por ese solo hecho, en algo así como un anatema. Y es que además, para ser honestos, los tribunales lo hacen con alguna frecuencia. Basta ver, por ejemplo, en delitos sexuales que involucran menores, fallos de la Corte Suprema, o de este mismo tribunal, que citan libros de expertos en sicología infantil o sicología forense para soportar la fiabilidad o no del testimonio de un niño supuestamente abusado. Ninguno de los jueces que suscriben tales providencias son sicólogos, ni han tenido entrenamiento clínico en atención de menores abusados, y tal vez ni hayan visto, siquiera como auxiliar, una materia de sicología en el pregrado, pero eso no es obstáculo para que él, que va a decidir, quiera tantear lo que los expertos de la sicología deponen antes que engullir entero las conclusiones de un perito como si lo que este dijera fuera infalible palabra divina.

5.2.2. También se puede hacer en la otra vía: un médico envuelto en un proceso penal puede hacer, por qué no, una sesuda averiguación, de las exigencias del tipo objetivo y subjetivo, de la estructuración antijurídica, del juicio de reproche, de los antecedentes jurisprudenciales que hoy están a la mano en múltiples sitios de la internet, etc., y presentar una alegación incluso más profunda, desde el punto de vista jurídico, que su propio defensor. No es una herejía que el profesional de una ciencia explore otra. Tener uno o varios títulos no da, a quien los detenta, el don del eterno acierto en todo lo que profese. Ejemplos de expertos, con largos años de estudio e investigación, que yerran en sus evaluaciones y predicciones los hay por doquier, y un juez sensato debe tener presente tal realidad.

5.2.3. Se insiste. El conocimiento privado no se equipara con el conocimiento general y especializado. El conocimiento privado es el que el juez tendría, por ejemplo, como testigo, él mismo de los hechos, como perito, él solo, de las condiciones de salud de una víctima y de su atención por un médico. No es eso lo que ocurre aquí por más de que, con cierta sorna, se resalte que el juez, en una candorosa declaración, haya dicho que encontró un 
documento sobre el adecuado tratamiento de la dolencia de la víctima, luego de una "ardua labor" de búsqueda, que algún defensor infiere no fue más que una búsqueda en Google. Entre otras cosas, el internet es un mundo sumamente amplio, y contrario a lo que se cree, además de basura, hay contenidos científicos de enorme valor que esa red ha permitido difundir casi que con el precio único de saber navegar por dónde se debe.

5.2.4. Sin embargo, para dejar las cosas en claro, el tribunal analizará la responsabilidad de los acusados no con base en ese protocolo, no porque estime que ese documento, cosechado en una república de condiciones sociales y políticas harto similares a las nuestras, no pueda brindar algunas luces para clarificar el caso, sino porque el caso mismo es tan rico en aportes probatorios, que inmiscuirse en una averiguación científico-médica de cómo se trata esta dolencia en México resulta francamente inútil.

5.2.5. Cuando se buscan fundamentos extraños a eso que llamamos el "acervo probatorio", se puede caer en el despiste del juez de primera instancia al querer buscar la "verdad" del caso en un protocolo extranjero y no en la prueba practicada. Lo que sí hay que dejar claro es que, si en nuestro país, tal protocolo no existe, no significa, para nada, que los aquí residentes deban someterse a un peor nivel de atención en salud cuando de dolencias testiculares se trate. De lo contrario, habría que decir que quien sufra un dolor testicular mientras está en México "tiene derecho" a un mejor tratamiento que si está en Colombia, simplemente porque en el país azteca se ha promulgado un protocolo sobre una patología y aquí no. En otras palabras, la adecuada atención en salud no debe depender de que el médico tenga un protocolo, así como el abogado tiene un código, sin el cual el tratamiento del paciente deba ser de menor categoría. Un protocolo es una guía que sirve de ayuda y de futura evaluación, pero la lex artis, en materia médica, no resulta inexistente, si tales protocolos no han sido formalmente promulgados.

De cualquier manera, el papel del juez en esta clase de asuntos no es hacer las veces de erudito supremo para dictar ex cathedra, sobre la opinión de los peritos que han participado en el caso, el "diagnóstico correcto". No. El juez no es, en este tipo de gestas, un imponderable maestro médico que dicte el diagnóstico correcto, sino que su papel es determinar, con base en todas las pruebas aportadas (que no son solo los peritajes), si la acción u omisión de los acusados violó o no un deber de cuidado, y, si con ello, un riesgo ilegítimo, no querido (pero sí previsible o previsto), se concretó en un resultado dañoso típicamente relevante.

\subsection{El dictamen de medicina legal}

5.3.1. Central a la postura de la fiscalía es el dictamen emitido por la doctora LMTP', quien es Médica Forense con especialización en Bioética, y quien hace parte del Grupo de Responsabilidad Profesional del Instituto de Medicina Legal. Además de haber sido incorporado, fue leído, íntegro, en el juicio ${ }^{10}$. Aparte del léxico médico que, como es obvio, utiliza, cualquiera que lo lea no tardará mucho en entender lo que esta profesional nos dice: que los tres médicos acusados no actuaron de acuerdo a su lex artis.

Este entendimiento viene de frases que ella soporta en su evaluación particular y en literatura médica. Así, nos dice cosas de las que difícilmente se puede disentir. Por ejemplo, que "[d]ada la importancia de preservar la fertilidad, las lesiones traumáticas de los testículos merecen atención cuidadosa." Es una conclusión más que razonable,

${ }^{9} \mathrm{CD} 4$, feb. 23, pista única, récord 19:21 y ss, y fls. 188-199 carpeta uno.

${ }^{10}$ Teniéndose una copia escrita, no era necesario leerlo todo, pero la fiscalía insistió en ello. 
motivo por el cual, en materia de urgencias, exige una atención prioritaria. La misma profesional agrega:

El diagnóstico adecuado de estas lesiones se hace mediante el relato y el examen físico. La ecografía escrotal con evaluación del flujo con Doppler ayuda particularmente con el diagnóstico para determinar la naturaleza y las repercusiones de una ruptura testicular inadvertida. La sensibilidad y especificidad del ultrasonido en esta situación ha sido reportada en 93.5 y $100 \%$ respectivamente...

Hacer doppler testicular durante el ultrasonido puede proveer información sobre el estado de los vasos de los testículos...

Otras imágenes radiológicas como gammagrafía o resonancia magnética pueden usarse para obtener información adicional. La ultrasonografía escrotal con el solo hallazgo radiológico de un patrón ecográfico heterogéneo del parénquima testicular con pérdida de la definición del contorno, es altamente sensible y específico para el diagnóstico de ruptura testicular a diferencia del dudoso examen escrotal. Sin embargo, el diagnóstico definitivo de ruptura testicular se hace en el quirófano y el tiempo es un factor para la preservación testicular ${ }^{11}$.

En otras palabras, si un varón llega con una afección testicular como la que aquí padeció el niño DSMR, de escasos tres años, lo que la profesional de medicina legal nos está diciendo es que la ciencia médica tiene a su disposición una serie de posibilidades para tener el diagnóstico correcto, y entre tales posibilidades, además del reconocimiento físico, estima ella, son recomendables una serie de exámenes, siendo la exploración escrotal la más segura de todas. Si leemos bien, este dictamen no está diciendo que, forzosamente deban ordenarse todos esos exámenes, pero sí que la ciencia médica ahora (y con más veras en una ciudad como Bogotá, que tiene importantísimos centros médicos), tiene un ramillete de opciones para hacer un buen diagnóstico. Por eso es por lo que, la misma profesional advierte:

Si no se tiene la suficiente suspicacia, el cuadro se va a mal interpretar como un evento traumático, con resultados catastróficos.

5.3.2. Ahora bien; aunque las anteriores notas pueden sonar un poco técnicas para los no familiarizados con las ciencias de la salud, la misma perito nos recuerda que se trata de un asunto no nuevo para los médicos:

Las torsiones relacionadas con trauma fueron descritas desde el siglo 19 por Mikulicz y Gervais y datos recientes sugieren que el trauma puede generar el 5 a $6 \%$ de los casos de torsión testicular.

Asimismo, nos dice esta perito que la presencia e incluso la ausencia de dolor son indicativos de posibles complicaciones:

${ }^{11}$ Fls. 195-196 carpeta 1. 
El dolor que suele ser de inacción súbita, adquiere su máxima intensidad en las primeras horas de la torsión testicular, para llego (sic) estabilizarse o aun a disminuir con el tiempo.

Y más adelante indica:

Por lo tanto, siempre se debe considerar como primera opción diagnóstica (se refiere a la torsión testicular) y se deben agotar todos los recursos que se tengan a mano para definir y descartar este diagnóstico.

De nuevo, no está afirmando esta profesional, como pareciera inferirlo algún sector de la defensa, que ineludiblemente ante un dolor testicular es una torsión lo que se ha presentado, sino que nos está explicando algo totalmente razonable para un profesional de la salud: este debe agotar todos los recursos que tiene a la mano para que su diagnóstico sea certero. En otras palabras, cuando existe un dolor de esta categoría, la función del médico no es desprenderse del paciente enviándolo a casa con una fórmula de analgésicos.

5.3.3. Y es que la experiencia de cualquiera de nosotros, con nuestra propia salud muestra que, en múltiples ocasiones, tras regresar por una dolencia no apaciguada con una primera fórmula y examen, el galeno de turno, con la sana idea del descarte, dispone repetir un análisis. No estamos diciendo que esta sea una regla de la experiencia que el tribunal quiera traspasar a la ciencia médica, sino que lo que ha advertido la doctora LMTP, médica forense del Instituto de Medicina Legal, no es nada irreflexivo ni traído de los cabellos, sino por el contrario, una conclusión sensata.

\subsection{Conclusiones expertas que armonizan con el dictamen de medicina legal}

5.4.1. Aunque en nuestro derecho probatorio no tiene cabida el principio testis unus, testis nullus, lo usual es que sobre una conclusión (más si es de orden científico) el juez perciba mayor tranquilidad si ella es corroborada por varias personas, o expertos. Pues bien, la conclusión de que, en eventos como el trauma que padeció el niño víctima en este caso, se debe proceder con sumas cautela y perspicacia, no está huérfana de compañía probatoria en este caso. La fiscalía, en ejercicio de una meritoria táctica, trajo al juicio a la doctora $\mathrm{AXDS}^{12}$, nada menos que la pediatra que finalmente descubrió la torsión en el testículo izquierdo de DSMR en la Clínica San Rafael de Bogotá. Ella, una especialista en cirugía pediátrica, explicó ${ }^{13}$ :

Cuando tenemos un paciente como el paciente que estamos en este caso y consulta por un cuadro de dolor testicular asociado a cambios inflamatorios eso tiene una definición en medicina, una definición general... en este caso lo denominamos síndrome ínguino escrotal agudo. Es un nombre general porque, en verdad, es muy pocas las veces que podemos tener absoluta certeza antes de entrar al procedimiento quirúrgico, específicamente qué entidad es... una de las causas, que no es la más frecuente, de síndrome ínguino escrotal agudo es la torsión testicular. Y cuando uno piensa, está pensando entre las posibilidades, que hay una torsión testicular, estamos hablando de una emergencia quirúrgica.

Y sobre la importancia de proceder a tiempo, la misma doctora D dijo ${ }^{14}$ :

\footnotetext{
${ }^{12} \mathrm{CD} 2$ y $3, \mathrm{Feb} .23 / 15$, pista $1^{\mathrm{a}}$, récord 31:33 y ss.

${ }^{13}$ Ibídem, récord 46:28 y ss.

${ }^{14}$ Ibídem, récord 48:20 y ss.
} 
Más o menos en promedio lo que está reportado en la literatura es que si un paciente llega con un síndrome ínguino escrotal y lleva más de 6 horas de evolución es, la mayor probabilidad, que haya una necrosis al hallazgo quirúrgico. Entonces, un síndrome ínguino escrotal se comporta como una urgencia y es entonces necesario llevarlo a exploración escrotal.

Y en torno a lo que semejante dolor significa, la misma profesional anotó:

Pregunta: ¿un dolor escrotal puede ser signo de torsión? Respuesta: claro, es lo que estaba refiriendo anteriormente. Como les decía el síndrome ínguino escrotal tiene muchas causas. Entre esas está la torsión testicular, pero no es la causa más frecuente.

Como en el caso particular analizado, el del niño DSMR, había un antecedente, pues el niño ya había sufrido un golpe similar en julio, la médica opinó ${ }^{15}$ :

Pero el antecedente, que el niño haya venido presentando dolores testiculares a repetición lo que nos debe hacer pensar es que estamos ante un síndrome de torsión testicular.

Y más adelante precisó ${ }^{16}$ :

Aunque no es la causa más frecuente, es una causa probable porque puede ponerse en riesgo el testículo y por eso lo llevé a una exploración escrotal que hace parte de nuestras herramientas de diagnóstico.

5.4.2. Ahora bien; no todo lo informado por la doctora $\mathrm{D}$ armoniza con las conclusiones de la forense de Medicina Legal. Así, por ejemplo, respecto de los exámenes recomendados en un caso como este, la doctora D declaró ${ }^{17}$ :

Realmente hay muchos cuestionamientos en la literatura (médica) y es cuando estamos hablando de niños prepúberes, antes de la pubertad. Por ejemplo, una de las herramientas que tenemos es realizar la ecografía Doppler testicular en el caso específico en que estemos pensando en una torsión testicular. Lamentablemente, la ecografía Doppler no nos sirve en niños menores porque el tamaño del testículo si es de menos de un centímetro cúbico, de menos de dos centímetros cúbicos de volumen, realmente es muy difícil percibir si esa irrigación es normal o está disminuida, y entonces no puede concluirse, con ese examen, si hay o no hay una torsión testicular.

Una lectura ligera del dictamen de Medicina Legal, contrastado con la anterior afirmación, haría pensar que el primero está equivocado. Sin embargo, sin ser lo apropiado examinar un testimonio solo a pedazos, bueno es escuchar, de cara a un niño de tres años, como lo es la víctima en este caso, lo que la misma doctora D expuso ${ }^{18}$ :

Cuando tenemos un niño que vemos, por ejemplo en el caso en que me llega, y está con esa sintomatología y yo, como en el caso, yo consideré que era un síndrome ínguino escrotal, la herramienta que tengo es la exploración escrotal. Es la única herramienta que tengo para visualizar, directamente, si hay torsión, si hay epididimitis, si hay trauma por estallido testicular, o si hay otra cosa.

\footnotetext{
${ }^{15}$ Ibídem, récord 52:41 y ss.

${ }^{16} \mathrm{Ibídem}$, récord 57:33 y ss.

${ }^{17} \mathrm{CD} 2$ y 3 , Feb. 23/15, pista $1^{\text {a }}$, récord 55:37 y ss.

${ }^{18}$ Ibídem, récord 56:35 y ss.
} 
Es decir, si vemos bien, la opinión de la doctora D nos está hablando de un examen mucho más profundo que la mera ecografía Doppler, y es, nada menos que, la exploración escrotal que fue justamente lo que ella hizo al intervenir quirúrgicamente al niño DSMR. Bien escuchado, lo que depuso la doctora Duarte va mucho más allá de la conclusión asumida por Medicina Legal.

5.4.3. De cualquier manera, no estamos afirmando, ni por asomo, que el testimonio de la doctora D haya sido una ratificación del concepto de Medicina Legal. Los ojos del tribunal no son discriminatoriamente selectivos sobre este particular. Por el contrario, su declaración, bastante prudente y profesional, mostró que, ante una dolencia testicular, alternativas de diagnóstico distintas de la torsión, como la epididimitis, no se podían descartar ${ }^{19}$ :

El examen físico es lo más importante. Tenemos, aquí hay varias cosas importantes y es que es un niño de tres años. Entonces, como les decía, la torsión testicular no es lo más frecuente. A esta edad, lo más frecuente son los procesos inflamatorios como las epididimitis. Obviamente en medicina nada es absoluto.

El tribunal quiere hacer énfasis en la última parte de esta transcripción: “Obviamente, en medicina, nada es absoluto", lo cual corrobora la mente abierta que ha de tenerse a la hora de fabricar un atinado diagnóstico. Esta conclusión, la ratificó la doctora D, en el contrainterrogatorio formulado por el abogado defensor del doctor FL; veamos ${ }^{20}$ :

Pregunta: ... un síndrome de estos puede tener muchas causas. Respuesta: sí señor... Pregunta: una de las causas poco frecuentes en niños de esta edad es la torsión testicular. ¿Correcto? Respuesta: correcto. Pregunta: que cuando se tiene un trauma de estos se debe pensar en otras posibilidades, ¿correcto? Respuesta: Sí señor. Pregunta: si se considera una epididimitis por trauma, la pregunta sería, ¿cuál debería ser el tratamiento? Respuesta: ¿Cuándo tienes una epididimitis? Pregunta: cuando se considera una epididimitis post trauma, ¿cuál debería ser el tratamiento? Respuesta: manejo antiinflamatorio oral con hielo local, antiinflamatorio local y reposo. Pregunta: una pregunta, la torsión testicular se puede dar sin trauma. Respuesta: claro, es más, la mayoría, mejor dicho por no decir todas, pero la gran mayoría de las veces, una torsión testicular se da sin trauma.

Sin embargo, para no crear falsas ilusiones respecto de la alternatividad en el análisis de hipótesis que hizo la doctora $\mathrm{D}$, no hay que olvidar la siguiente parte del mismo contrainterrogatorio cuando esta profesional expresa:

Lo que quería decirle a la fiscal era: como los hombres es frecuente que tengan traumas. Entonces, si tú tienes una torsión testicular, y te acuerdas que tuviste un trauma, es frecuente que uno haga la asociación. Pero no necesariamente hay una causa-efecto. Pero si tú tienes la condición anatómica, o sea que no está bien fijo el testículo, ¿sí? Esa alteración anatómica que favorece una torsión puede un trauma favorecer una torsión testicular.

\footnotetext{
${ }^{19}$ Ibídem, récord 54:51 y ss.

${ }^{20} \mathrm{CD} 2$ y 3 , Feb. $23 / 15$, pista $2^{\mathrm{a}}$, récord 13:27 y ss.
} 


\subsection{Los embates al dictamen de medicina legal}

5.5.1. Un sector de la defensa, en un ejercicio sano y juicioso de su derecho de contradicción, ha traído otros expertos para demeritar las conclusiones del dictamen de medicina legal. Se trata, por supuesto, de una estrategia previsible, respetable y hasta deseable en el marco del proceso penal. En este asunto, estos embates son de tres tipos: (i) unos apuntan a las formalidades del dictamen, (ii) otros al método de adquisición del conocimiento hecho explícito en el experticio y (iii) finalmente, otros tienen que ver con la conclusión propia de responsabilidad de los médicos acusados que la perito de Medicina Legal afirma. En esta parte de la providencia, nos referiremos a los primeros dos, en tanto el último tercio de arremetida lo abordaremos más adelante.

En efecto, en el juicio se contó con la declaración de la doctora GMJR ${ }^{21}$, médica, especialista en anatomía patológica y con experiencia como patóloga quirúrgica. Ella evaluó el dictamen pericial de Medicina Legal, esto es, hizo una especie de peritaje al peritaje en el que se basó la acusación. De lo expuesto por la doctora J, y de otras críticas, se extrae que, un sector de la defensa, estima que el peritaje base de la acusación tiene, cuando menos, tres tipos de falencias:

- No seguimiento de requisitos formales dispuestos en una circular interna del Instituto de Medicina Legal, por ejemplo la no documentación de interconsulta en particular con los urólogos GM y LW.

- El que la forense no sea ni pediatra, ni uróloga.

- Ausencia de referencia, en las historias clínicas consultadas, a un cuadro clínico de torsión testicular.

Ninguna de estas tres máculas pasa de ser observaciones que podrían servir al Instituto de Medicina Legal para hacer experticios con mayor técnica y soporte, pero nada en ellas le resta, en la visión del tribunal, la credibilidad que el particular análisis forense comporta. Veamos:

Que la experta de Medicina Legal no haya dejado constancia escrita, en un documento distinto del propio peritaje allegado a este proceso, de las conversaciones que tuvo con otros profesionales, como por ejemplo, con el doctor GM, no le quita fuerza a las conclusiones del experticio. El tribunal no entiende el aspaviento que genera el que un médico forense, para tener mayor seguridad sobre una opinión científica, consulte a un colega o a un especialista. Es cierto que lo ideal sería, como la misma perito reconoció ${ }^{22}$, que existiera un procedimiento más formal en Medicina Legal, pero que un profesional busque una respuesta a un problema concreto propio de su ciencia, confirmando sus hipótesis con otros profesionales, no tiene nada de irregular ni de extraño, ni en la medicina ni en cualquier otra ciencia.

¿Acaso no lo hacemos los mismos abogados, incluidos nosotros los jueces, cuando tenemos un caso difícil? ¿Cuál es el juez que jamás ha consultado con un compañero algún asunto intrincado? Lo hace un ingeniero cuando quiere corroborar un cálculo y le pregunta a un compañero que conoce del tópico, o un contador que para estimar un porcentaje de tributación ratifica con otro contador sus operaciones matemáticas. Es algo propio del "colegaje" profesional.

${ }^{21}$ CD 19-20. Abr. 13/15, pista $1^{\text {a }}$.

${ }^{22} \mathrm{CD}$ 6-7, feb. 23, pista única, récord 43:34. 
¿Dónde está la regla probatoria según la cual un profesional, incluido un perito de Medicina Legal, tiene que saberlo todo y no puede utilizar un instrumento de la tecnología del siglo pasado, como lo es el teléfono, para aclarar con un condiscípulo una posición científica que queda así robustecida? En nuestro mundo abogadil, tan propenso al papeleo, si esas conversaciones no aparecen escritas y suscritas en un papel, ¿entonces no es válida la evaluación posterior que el forense hace con esa información? ¿Deben ser los peritos de Medicina Legal algo así como sabios sublimes y acabados que, en caso de consultar con otros profesionales de la salud, deban dejar una huella documental de todas y cada una de sus peripecias de averiguación? Por supuesto que la respuesta del tribunal es negativa a estas preguntas.

No podemos exigir que cuando un experto de Medicina Legal consulta a otro para desvanecer sus dudas o afianzar sus conclusiones, tenga que dejar un tipo de "cadena de custodia" de todas las consultas o interconsultas como aquí se le han llamado. Menos que tengamos que poner a los expertos de Medicina Legal a traer los diplomas (con sellos y apostillas) de los colegas con los que hayan conferenciado. Lo dijo la misma perito de Medicina Legal en el contrainterrogatorio cuando se le preguntó si tenía los títulos de los médicos que había consultado:

Al parecer la pregunta va diciendo que la documentación que debería como si el señor defensor tuviera un reglamento diferente al que yo manejo porque en ningún momento para los informes periciales se me exige adjuntar una documentación en relación a los créditos de los médicos ni siquiera del mío propio ${ }^{23}$.

Por el mero hecho de que no tengamos un papel firmado por los doctores $\mathrm{M}$ y W no podemos colegir, sin más, que la afirmación de haberlos consultado incluida en el dictamen de Medicina Legal sea contraria a la verdad. Si alguien hubiera tenido acá siquiera un barrunte de que la doctora TP mintió al escribir que, para fortalecer mejor su científica conclusión, dialogó sobre el asunto con un par de urólogos, bien hubiera podido denunciarlo, pero nadie lo ha hecho sencillamente porque esa interconsulta sí se realizó, y los resultados de esa conversación quedaron escritos, y ratificados con el juramento de la perito en el juicio.

5.5.2. De otro lado, los jueces penales en Colombia no son auditores de la observancia irrestricta de las formalidades y capítulos que deben tener los dictámenes que suscriben funcionarios de Medicina Legal. Si la doctora TP no siguió los formulismos establecidos por una circular del Instituto de Medicina Legal, con todo respeto debemos decir que quien esté contrariado con ello puede buscar un llamado de atención de los superiores de la funcionaria, pero para que esos supuestos errores minen la credibilidad del dictamen no basta simplemente con decir que este "no siguió las directrices de tal o cual circular". Si vamos a aplicar un rasero formalista a los dictámenes de Medicina Legal, difícilmente quedarían algunos en pie.

5.5.3. Finalmente, el que la doctora TP no sea uróloga, no le resta valor a sus conclusiones. Primero que todo, está ella (por lo menos al momento del dictamen) en el giro ordinario de la evaluación propia de la responsabilidad profesional; trabaja, justamente, en el grupo de responsabilidad profesional y hacer este tipo de tareas no es algo que ella haga de vez en cuando, sino que es su oficio diario. Segundo, fue tan cuidadosa que para ratificar sus inferencias científicas, habló con un par de urólogos, y no ocultó tal consulta, ni los nombres de los consultados. Y tercero, muchas de las recomendaciones que en general ella encontró

${ }^{23} \mathrm{CD} 5$, Feb. 23/15, récord 4:56 y ss. 
razonables para un caso de dolor testicular como el que afrontó el niño DSMR, tienen más valía tratándose de una experta en bioética: si alguien que no es urólogo pediatra, con una mediana averiguación, sabe de varios cuidados aconsejables ante una complicación como la que ese infante padeció, con más veras un especialista en pediatría.

\subsection{Responsabilidad particular}

En un caso como este, donde la intervención de tres médicos acusados no ha sido simultánea, más aún donde cada uno atendió al niño lesionado en una institución diferente y en tiempos sucesivos pero distintos, no es digno de patrocinio un fallo donde la responsabilidad de los tres galenos no se analice por separado. En este caso, la responsabilidad penal, siendo individual, exige un análisis particularizado de la actuación de cada uno. No hay una responsabilidad "en masa" de ellos.

Y ese análisis no puede basarse, desde ya hay que decirlo, exclusivamente en la prueba científica. El proceso penal por responsabilidad médica no puede convertirse en una especie de guerra de peritos, para ver, cuál es el que más enjundia tiene en sus experticios, sino que tiende a determinar si hubo culpa o no, y esa determinación le corresponde al juez, que es abogado, mas, para nada, el médico con el mejor de los diagnósticos. Por ende, descartar, sin más, las declaraciones de los testigos no expertos que han vivenciado el hecho es un error de cálculo y de valoración.

Una lesión y su adecuado o inapropiado tratamiento médico es un asunto especializado, pero a la vez es un asunto humano, ordinario si se quiere, que quien lo ha padecido en carne propia también "conoce". Así, un niño que apenas comienza a vivir, que tal vez para esa época no sepa leer sino un par de palabras, es quien verdaderamente ha sentido y padecido el dolor. Su conocimiento y el de su madre que lo ha acompañado no es de menos valía que el conocimiento especializado de los peritos. Ambos conocimientos (el del perito y el de las víctimas) tiene su propio espacio, pero el conocimiento del paciente, referido a su dolor, a lo que siente, a lo que vive, no es de menos entidad simplemente por no ser especializado. La adecuada concatenación entre ambos conocimientos, basada en el respeto mutuo, es clave para la preservación de la salud.

5.6.1. JPVB

La doctora JPVB fue la primera profesional que atendió al niño DSMR. Doña NYRB, la mamá del niño, resume la atención de esta profesional con las siguientes palabras:

Ella lo atendió ${ }^{24}$. Se me hizo curioso pues porque cuando uno como paciente va a un médico, al médico, pues el médico siempre lo debe revisar a uno. Ese día, la doctora ni cerró el consultorio, la puerta del consultorio. Yo entré con mi hijo. Me hizo subirlo en una escalera, en la escalerita que hay para subir a la camilla. En ningún momento ni siquiera lo tocó. Solamente me hizo bajarle el pantaloncito y con un esfero señalaba y me decía "yo lo veo bien, pero le voy a ordenar una ecografía... ecografía escrotal".

La señora RB cuenta que la doctora VB, en forma verbal, remitió al niño a pediatría, pero sin ninguna remisión por escrito:

Que lo valore un pediatra, yo soy médico general ${ }^{25}$... para que el pediatra lo revisara nuevamente, eso fue todo lo que ella me dijo.

${ }^{24}$ CD 23-1, feb. $23 / 15$, pista $2^{a}$, récord 35:26 y ss.

${ }^{25}$ Ibídem. Récord 38:10 y ss. 
Así, un hecho no desvirtuado es que la doctora RB consideró que el niño debía ser revisado por un pediatra porque ella era médico general. Sin embargo, no dio ni remisión por escrito, ni mucho menos algún canal para que la evaluación fuera inmediata. Tanto que cuando la madre, un poco inocentemente, llamó a su EPS (Compensar) para obtener la cita, se encontró con que tal orden, siendo verbal y no escrita, no activaba la posibilidad de tal consulta especializada.

La defensa de la doctora VB encaminó su estrategia sobre el hecho de que en la Cruz Roja, donde ella trabajaba, no existía la posibilidad ni de una atención a un nivel superior, ni una remisión, dentro de la misma institución, a servicios de urología pediátrica. Así, por ejemplo, tenemos el testimonio de la abogada $\mathrm{LMPA}^{26}$, Directora Ejecutiva de la Cruz Roja de Bogotá y Cundinamarca, quien fue clara en decir que su institución, para el momento de los hechos, no tenía servicio de urología ni de cirugía pediátrica ${ }^{27}$, ni tampoco el examen Doppler.

También tuvimos a la doctora $\mathrm{LPRG}^{28}$, directora departamental de salud de la Cruz Roja, seccional Bogotá y Cundinamarca, la que ratificó los limitados alcances del médico general, y que para el año 2007, la Cruz Roja solo tenía servicio de imágenes diagnósticas de baja complejidad. Anotó que no es del resorte del médico general, ordenar un "ecodoppler", pues este corresponde disponerlo al médico especialista en detectar varices en el testículo.

Asimismo, la defensa de la doctora VB trajo el testimonio de la sicóloga FEGC, quien es Coordinadora de Gestión Humana de la Cruz Roja seccional Bogotá y Cundinamarca²9; ella leyó una certificación de la vinculación que la doctora JPVB tuvo con La Cruz Roja para la época de los hechos (un contrato de prestación de servicios desde el 30 de junio de 2007 hasta el 10 de marzo de 2008).

¿Significa lo anterior que un médico general que, en el año 2007, estuviera trabajando en la Cruz Roja de Bogotá, en las instalaciones de esta entidad sobre la Avenida 68, estaba material o normativamente imposibilitado para remitir a un paciente a otra institución, en caso de que una emergente situación así lo ameritara? La respuesta es negativa, y para ello, los mismos testimonios traídos en favor de la doctora VB permiten colegir lo contrario. Así, LMPA ${ }^{30}$, Directora Ejecutiva de la Cruz Roja - Seccional Bogotá y Cundinamarca, en el contrainterrogatorio practicado por la fiscalía, dijo que sí existían "unos protocolos" cuando el paciente debía ser atendido por una instancia de nivel superior:

Se hace un proceso de remisión vía referencia ${ }^{31}$, donde se consulta a la aseguradora, a qué institución de nivel superior se debe trasladar. Pregunta: ¿Es decir que en un caso que lo requiera sí se puede hacer el traslado de urgencia a urólogo o pediatra? Respuesta: Cuando se requiere, se hace, sí señora.

Lo mismo hay que decir de LPRG ${ }^{32}$, directora departamental de salud de la Cruz Roja, quien informó que si un paciente requiere un tratamiento hospitalario de mayor nivel, el paciente se envía a urgencias, y desde allí se hace la remisión a la otra institución.

\footnotetext{
${ }^{26}$ CD $17-18$, mar 9/15, pista $1^{\text {a }}$.

${ }^{27}$ Ibídem. Récord 9:52 y ss.

${ }^{28} \mathrm{CD} 17-18$, mar 9/15, pista $2^{\mathrm{a}}$

${ }^{29} \mathrm{CD} 19-20$. Abr. $13 / 15$, pista $1^{\text {a }}$, récord $47: 30$ y ss.

${ }^{30} \mathrm{CD} 17-18, \operatorname{mar} 9 / 15$, pista $1^{\mathrm{a}}$.

${ }^{31}$ Ibídem. Récord 11:01 y ss.

${ }^{32}$ CD 17-18, mar 9/15, pista $2^{\text {a }}$
} 
Entonces, con el respeto que nos merece el señor abogado defensor de la doctora VB, no es cierto que ella estuviera profesional o institucionalmente impedida para dar una orden por escrito para que el niño DSMR fuera atendido, ese mismo día, por un . Si estuviéramos en una población de limitado alcance, enclaustrada en algún sector provinciano del país, tal vez una remisión inmediata sea más complicada de ordenar. Pero en Bogotá, donde se supone tenemos, a varias de las mejores instituciones de salud del país, y hasta de Latinoamérica, considerar que una médica general no puede hacer una remisión escrita a un especialista, simplemente porque en la misma IPS no se presta tal especialidad, es, en opinión del tribunal, inexcusable.

También es injustificable que la delicada revisión que del estropeado testículo de un niño la hubiera hecho la profesional, como lo ha relatado la madre del niño, sin palparlo, sin tocarlo, y apenas señalándolo con un lapicero, sin respetar, siquiera, la privacidad del infante, con la puerta del consultorio abierta, como si no tuvieran los niños, tan personas como nosotros, el derecho a la intimidad en una revisión médica.

\subsubsection{JGFL}

5.6.2.1. La prueba traída para defender al doctor JGFL apunta a considerar que el diagnóstico que este realizó, consistente en una inflamación del epidídimo del niño, fue un diagnóstico correcto. En la apelación, el abogado defensor hace una distinción entre epididimitis y torsión testicular. El sufijo "itis", como se sabe, es una partícula de raíz griega que significa inflamación. Así, por ejemplo, hablamos de "apendicitis" para referirnos a la inflación de la apéndice, o de hepatitis que es la inflación del hígado o de otitis que es la inflamación del oído. El epidídimo es un órgano en forma de tubo que está encima del testículo. Lo que vio el médico FL, según su defensor, fue una inflamación del epidídimo, es decir, una epididimitis.

En soporte de esta tesis, había declarado la pediatra OLB ${ }^{33}$, luego de rendir concepto por escrito, el cual emitió, no sin antes revisar la documentación del caso, incluida la historia clínica firmada por el médico FL. Ella concluyó que no se podía asegurar que el menor aquí victima hubiera sufrido una torsión testicular para el momento en que fue atendido por el doctor JG. Frente al punto de si el menor requería otro examen, esta profesional afirma que ella no le hubiera tomado otro examen ${ }^{34}$ de acuerdo a la información que tenía en ese instante.

En similar sentido, se contó con el dictamen del doctor JHCM, que relata que no es frecuente una torsión testicular posterior a un trauma escrotal. Basado en la historia clínica, concluyó que al momento de ser el paciente atendido por el doctor GF no había una expresión clínica de torsión testicular aguda.

También se cuenta con el propio testimonio del doctor JGFL ${ }^{35}$ donde reconoce que el menor era un paciente que consultaba en horas de la noche porque en horas de la mañana había tenido un trauma en uno de sus testículos ${ }^{36}$. Dice que pudo tocar al menor y que el niño pudo caminar unos tres metros, y que no tenía taquicardia. "El niño ni siquiera tenía dolor cuando yo lo vi" ${ }^{37}$. Cuando se le preguntó por qué no había pedido una nueva

\footnotetext{
${ }^{33}$ CD 19-20. Abr. 13/15, pista $2^{\mathrm{a}}$, récord 4:40 y ss.

${ }^{34}$ Ibídem. Récord 29:50 y ss.

${ }^{35}$ CD 12-13-14, mar. 9/15, pista $1^{\text {a }}$, récord 19:03 y ss.

${ }^{36}$ Ibídem. Récord 22:02 y ss.

${ }^{37}$ Ibídem. Récord 46:11 y ss.
} 
ecografía, dijo que el paciente, en ese momento estaba sin dolor, asintomático. Según el doctor F, la idea de haberse tenido que tomar una segunda ecografía no resultaba pertinente dados sus hallazgos clínicos en este caso, y para soportar su argumento puso el ejemplo de los traumas craneoencefálicos.

Tenemos así la construcción de una tesis defensiva que se basa en que el diagnóstico realizado por el doctor FL, que fue el de una epididimitis y no el de una torsión testicular, fue correcto, según el examen físico que realizó, el cual arrojaba como resultados falta de dolor, paciente asintomático. De ser así, como el doctor FL revisó al niño en la noche del jueves 11, y el sábado 13 el niño fue intervenido quirúrgicamente, y para entonces, no solo ya tenía más que una torsión testicular, sino muerta por completo la gónada izquierda, uno tendría que colegir que, por alguna razón, aún no explicada en toda la ciencia que se le ha aplicado a este caso, la torsión ocurrió, en forma repentina, el viernes, como venida de un desconocido infierno de azarosos infortunios.

Al respecto, es cierto que el dictamen del urólogo JHCM aborda el tema pero para informar que, aunque la literatura médica sí describe que una torsión se puede presentar después de un trauma escrotal, eso no es lo que ocurre con frecuencia, tanto que él, que por lo menos tiene un caso de torsión al mes, no ha visto ninguna torsión después de un traumatismo contundente genital ${ }^{38}$. Pero ahí se ha quedado la explicación, y en verdad ante la nebulosa de saber en qué momento fue que la gónada izquierda del niño se enroscó, no podemos olvidar que entre el jueves 11 y el sábado 13 un mismo dolor testicular, solo que incrementado a través del tiempo, una misma inflamación solo que acrecentada con el pasar de las horas, solo vino a parar cuando una torsión testicular fue descubierta.

5.6.2.2. También es cierto que el urólogo CM, como los otros expertos que han declarado en favor del doctor FL, sostienen que la evidencia clínica a la mano de este último no mostraba signos de torsión, sino de inflamación del epidídimo. El problema que tiene esta hipótesis, con el respeto que nos merecen los profesionales que la auspician, es que ella está basada en la historia clínica elaborada a instancia del mismo doctor FL, y sobre la versión de este. Por supuesto, no quiere decir el tribunal, ni por asomo, que porque la versión la haga un procesado, no sea ella digna de crédito, ni que no se pueda estimar creíble la historia clínica elaborada a instancias de un médico involucrado en un proceso penal. En absoluto tal podría ser nuestra apreciación pues, para nada, en penal, se puede presumir la responsabilidad del acusado.

El quid del asunto es que la afirmación central del doctor FL, según la cual el paciente llegó asintomático y sin dolor, se choca de frente con la prueba que con creces muestra que el niño DSMR arribó, en la noche del jueves 11 de octubre, al consultorio del doctor FL, en el Hospital San José, no porque su madre estuviera sobrerreaccionando y lo llevara, en exceso de cuidado materno, a otra visita de chequeo médico. No. La madre había lidiado todo el día con el dolor del niño, había intentado, infructuosamente, la cita pediátrica que verbalmente había sugerido la doctora de la Cruz Roja, y el Ibuprofeno que le había recetado esta última no había apagado esos gemidos, ni reducido la inflamación. Cuando una mamá está expuesta al llanto de su hijo por la inflamación de uno de los testículos de su pequeño, su conocimiento, el de madre, tiene un valor excepcional que la justicia no puede pasar por alto, sin más, máxime cuando no era la primera vez que ella lidiaba con igual dolencia.

\footnotetext{
${ }^{38}$ Fl. 294 carpeta 1.
} 
Para el tribunal, no es cierto, como ha querido hacer ver el doctor FL, con el respeto que nos merece, que el niño hubiera llegado sin dolor a su consultorio. Tal vez podía caminar, pero intentar vender la idea de que el niño iba sin dolor, asintomático, aun cuando haya quedado escrito así en la historia clínica, no es lo que razonablemente se puede concluir en este caso. Lo escrito en una historia clínica no es letra infalible. Si el niño hubiera llegado sin dolor, sería válido preguntarse ¿por qué entonces tuvo que seguir el tratamiento con el antiinflamatorio Ibuprofeno? Y más aún ¿por qué el siguiente médico lo que hizo fue buscar un analgésico más potente? Si el llanto del niño hubiera cesado, si el Ibuprofeno ordenado en la mañana hubiera tenido efecto positivo, doña NY no hubiera llevado a su niño, en horas de la noche, a perder tiempo en un hospital. Si escuchamos el testimonio de esta mamá, confirmamos esta conclusión:

(La fiscalía le pregunta a la madre cómo fue la revisión que al niño hizo el doctor FL). Pregunta: ¿Cómo lo revisó? Respuesta: Lo subió en una camilla ${ }^{39}$. Él pues sí le revisó el testículo a mi hijo. Pregunta: ¿Cómo estaba el testículo? Respuesta: inflamado y rojo. Cada vez era más el aumento y se veía la diferencia del uno al otro (testículo). Yo le entregué la ecografía y le comenté que hace doce meses mi hijo le había sucedido un golpe en el mismo testículo...

Él me dijo que debía sacarle cita. Me dio una orden. Me dijo: "pida una cita por urología pediátrica"... me dijo: "le doy esta orden para que llame y pida cita de urología pediátrica", pero en ningún momento le escribió "prioridad"...

Él lo tocó, lo palpó y me dijo que estaba normal. Lo único que hizo fue, eso eran como las diez, nueve y media de la noche, bajó a mi hijo de la camilla, y lo puso a caminar en medias por ese piso tan frío, y cruzado de brazos y me decía: "no, yo lo veo bien".

Luego, cuando la fiscalía buscó precisar los hechos, doña NY, refiriéndose al doctor FL, informó:

Él ${ }^{40}$ me dio la orden y me dijo "siga con el Ibuprofeno"... o sea me la pasaba era dándole Ibuprofeno, Ibuprofeno que para el dolor, para el dolor, y no era más lo que le daban. Ningún otro examen, ni nada más. Pregunta: ¿Usted refirió que él la remitió a otro médico? Respuesta: sí señora. Pregunta: ¿A qué médico? Respuesta: Urología pediátrica. Pregunta: ¿Le explicó por qué? Respuesta: que para que lo revisara el urólogo. Solamente eso me dijo, que él es el especialista... me dio una remisión pero no decía "prioritaria", sino "cita por urología pediátrica" por consulta externa. Pregunta: ¿Usted llevó a su hijo al urólogo? Respuesta: Yo llamé... a solicitar la cita. Me dijeron que había citas para 8 días hábiles. Al ver que no podía conseguir consulta, por consulta externa como él me lo había dicho, yo llamé a la EPS de Compensar y solicité una cita con pediatría. Pregunta: ¿Por qué la solicitó? Respuesta: doctora, porque mi hijo seguía quejándose del dolor. El testículo ya era más inflamado, más rojo, ya parecía ver una ciruela. Pregunta: ¿a qué se refiere usted al "ver una ciruela"? ¿Qué aspecto tenía? Respuesta: roja ya como entre negra.

El doctor FL hace alusión, en su declaración, a traumas craneoencefálicos, mas sucede que ni la fiscalía, ni ninguno de sus testigos y peritos se ha referido a ese tema. El punto

${ }^{39}$ CD 23-1, feb. $23 / 15$, pista $2^{\text {a }}$, récord 40:35 y ss.

${ }^{40} \mathrm{CD} 23-1$, feb. 23/15, pista $2^{\mathrm{a}}$, récord 44:15 y ss. 
concreto aquí era un exasperado dolor testicular de un niño de tres años, no un trauma craneoencefálico. Claro, el doctor FL asegura que al examinar al niño, el pequeño no tenía torsión testicular ${ }^{41}$. Y tal pudo ser su apreciación, sobre todo porque cuando la madre del menor le habló del tema, con una respuesta hiriente y poco profesional, él le replicó a la señora: - Si usted es médico, ¿para qué me lo trae? No deja de ser irónico que el posible diagnóstico que una madre sin conocimientos médicos sugiere, sea nada menos que lo que realmente viene a tener el niño, pero que tiene que descubrirse mucho después de que tres profesionales de la salud han examinado al infante sin tino alguno.

Como el doctor FL no quiso ver lo que la madre sí veía y sentía que era el dolor del niño, como mientras la madre veía mal a su párvulo, pero el doctor lo observaba asintomático, luego del respectivo examen físico, no dispuso examen adicional alguno y lo devolvió para la casa. Y como el tribunal no tiene conocimientos médicos especializados, debe acudir, para evaluar esta decisión médica, a lo que otros profesionales de la salud traídos al juicio han expuesto. Al respecto, es clave el testimonio del médico radiólogo EM, quien interpretó la ecografía escrotal del menor en la Cruz Roja; para el momento de la imagen, el órgano que se veía afectado era el epidídimo, y con los hallazgos, en ese momento, no se determinaba una torsión testicular. Hasta ahí no hay discrepancia, pero el mismo doctor M fue más que claro, al responder a la fiscalía, que esa situación podía cambiar ${ }^{42}$ :

Pregunta: es decir doctor ¿que para ese instante (se refiere al momento de la ecografía) tenemos este examen? Respuesta: sí señora. Pregunta: es decir que en la noche si a mí nuevamente me chequean por este dolor, ¿esto podía cambiar? Respuesta: sí, en el tiempo, claro, lógico, es susceptible de cambiar. Pregunta: es decir, ¿este examen ya no me servía? Respuesta: pues todo depende del cuadro clínico que tuviera el niño en ese momento.

5.6.2.3. Y el mismo radiólogo dijo que los resultados de la revisión practicada al menor implicaban estar alerta ${ }^{43}$ :

Pregunta: acá tenemos unos hallazgos a los que ya hemos hecho referencia, ¿cierto doctor? Respuesta: sí. Pregunta: ¿esos hallazgos ameritaban estar alerta? Respuesta: lógico porque el niño, si no mejora, hay que volver a examinarlo y dependiendo de lo que haya encontrado, cómo haya sido su evolución, pues solicitar más exámenes. Pregunta: es decir, que ante evolución de estos hallazgos, ¿se requerían más exámenes, doctor? Respuesta: sí, si el niño había empeorado o por lo menos se queda sintomático, lógico que sí.

Pregunta: pero si ingreso, nuevamente, dos veces más a la clínica, con este antecedente clínico, con estos hallazgos, ¿me pueden referir que requiero más exámenes, doctor? Respuesta: sí, claro que sí. Pregunta: ¿Qué exámenes podría haber ordenado? Respuesta: repetir, ya lo había dicho, repetir la misma ecografía. Si ya hubiera hallazgos sospechosos de la presunción de la torsión testicular, pues hay otros exámenes como son el Doppler, la gammagrafía, o la resonancia magnética.

${ }^{41}$ Ibídem. Récord 55:15 y ss.

${ }^{42}$ CD 8-9, feb. 24/15, pista $2^{\text {a }}$ récord 18:21 y ss.

${ }^{43} \mathrm{CD} 8-9$, feb. 24/15, pista $2^{\mathrm{a}}$ récord 33:15 y ss. 
Si las cosas no evolucionan satisfactoriamente, debe tener uno un concepto, en este caso, de un cirujano. Pregunta: es decir doctor, que ¿se requería ser revisado el niño por un cirujano? Respuesta: por un urólogo, el especialista en esta materia.

Lo afirmado por el radiólogo EM solidifica la tesis de la fiscalía y muestra que el dictamen de Medicina Legal no es para nada alocado, sino que tiene un fundamento científico. Cuando el niño fue, el mismo día, por segunda vez al médico, del segundo médico se exigía mayor perspicacia. Lo que para el radiólogo era algo claro, vale decir, la realización de una gama de exámenes más allá del reconocimiento físico, no lo fue para el doctor FL, a quien le disgustó que la madre apenas preguntara por otro posible diagnóstico.

Es más, en una parte de su testimonio, el doctor FL sostuvo que el testículo no estaba inflamado ${ }^{44}$, que el testículo, cuando lo palpó, no tenía aumento de tamaño ni inflamación. Ya después, como se sabía que lo que los legos conocemos como testículo izquierdo sí estaba inflamado, en otras palabras, que al menos el escroto sí se notaba abultado, el doctor aclaró que lo que no estaba inflamado era la gónada. Se supone que a tal conclusión llegó tras ver este órgano del niño. Si la gónada está recubierta por una bolsa de piel, o el doctor F tenía un entrenamiento en urología que le permitía detectar el estado de órganos que están debajo del escroto, o confiaba en una ecografía que, tomada en la mañana, podía ya estar desactualizada en la noche.

Cualquiera haya sido la raíz de su conclusión, lo cierto es que, por alguna razón, dispuso, sí, una consulta con un urólogo pediatra, subespecialidad que él no tenía. Pero esa consulta la ordenó no con carácter prioritario. La copia de la historia que se nos ha allegado ${ }^{45}$, aun con las dificultades que en los legos genera la enredada letra con la que es usual que esas historias se confeccionen, no dice por qué es que esa cita con urólogo pediatra se ordenaba. Uno supondría que, siendo un conocimiento más especializado el de un urólogo pediatra, este tendría mayores elementos de juicio para tratar el dolor testicular del niño. Si él no tenía un conocimiento absoluto de la materia, tal vez un experto en urología de niños tuviera más éxito. Pero el problema, con ello, no fue la orden misma, sino el hecho de que se emitió sin ninguna prioridad muy a pesar de la delicada situación del menor que por segunda vez, el mismo día, acudía a ser atendido por un profesional de la medicina.

5.6.2.4. En que había que consultar un urólogo, es curioso, coincide la hipótesis defensiva del doctor FL con la que expresó la experta de Medicina Legal, y la que anotó el radiólogo $\mathrm{M}$, quien corroboró que esa consulta sí era necesaria. De lo escrito por el dictamen de Medicina Legal, se colige que, en casos como los que sufrió el niño DSMR, es mejor pecar por exceso de cuidado que por defecto. Ciertamente, ella llegó al extremo de advertir: "[t]odo escroto agudo es una torsión testicular hasta que no se demuestre lo contrario"46. Por eso es por lo que se debe "[a]visar de inmediato y sin pérdida de tiempo al Urólogo de turno" ${ }^{\prime 7}$ (resaltado nuestro). Tal vez esa presunción, redactada en términos casi que jurídicos, no sea compartida por los profesionales que han declarado a favor del doctor FL, incluido él mismo, pero en lo que sí coincide el comportamiento profesional de él, y el dictamen de medicina legal, es que la consulta con urólogo era necesaria, solo que para el doctor $\mathrm{F}$ no era urgente.

\footnotetext{
${ }^{44} \mathrm{CD} 12-13-14$, mar. 9/15, pista $2^{\mathrm{a}}$, récord 00:39 y ss.

${ }^{45} \mathrm{Fl} .246$ carpeta 1.

${ }^{46}$ F. 192 ibídem.

${ }^{47}$ Fl. 192 ibídem.
} 


\subsubsection{HRM}

5.6.3.1. Aunque no es función del tribunal pesar las culpas, tal vez donde mayor incuria se ve es en las omisiones del doctor HRM. Si la cirugía exploratoria que permitió concluir que el testículo izquierdo estaba muerto (necrosis) se hizo el sábado 13 de octubre, y el doctor HRM atendió al niño en la tarde del viernes 12, se puede colegir que para este viernes la torsión era ya un hecho. El doctor RM pudo descubrir, sí, una afección respiratoria del menor, tal vez asociada al hecho de llevar dos días seguidos llorando, pero fuera de recetar un analgésico más fuerte no hizo nada más.

En efecto, nos cuenta la mamá del niño que ese viernes la situación del párvulo empeoró y como tienen que hacer cientos de madres colombianas cuando no pueden pagar el costoso servicio de una medicina prepagada, llamó de nuevo a su EPS, Compensar. Imploró, otra vez, una cita prioritaria de pediatría y se la asignaron en una institución de Compensar ubicada en el barrio Villa Luz de Bogotá. Esto fue lo que vivió:

Llegué al consultorio ${ }^{48}$, me reporté, esperé que me hicieran el llamado. Entré con mi hijo. Y pues mi hijo quejándose. Yo lo llevaba en brazos y se estaba quejando. Decía que le dolía, que le dolía. Pregunta: ¿Cómo le día el niño? Respuesta: "mami, me lele, me lele, ayúdeme, ayúdeme" y se ponía las manos en sus testículos. Yo me sentía impotente porque es que ya había llevado a tantas partes a mi hijo.

Del comportamiento del doctor $\mathrm{H}$, esto dijo la mamá del niño:

Yo entré al consultorio. El doctor le bajó el pantalón, lo revisó, le tomó signos vitales. Pregunta: ¿le hizo palpación? Respuesta: Sí, y el niño se quejaba. Pregunta: ¿lloraba? Respuesta: Sí señora. Pregunta: ¿Y qué le dijo el médico? Respuesta: lo revisó, y yo le mostré la ecografía. Le comenté pues de que por el Hospital San José el doctor F me había dado una orden para urología. Entonces me dijo "sí. Llévelo". Pero él, en ningún momento, me dio otra orden u otro examen... Pregunta: ¿Le explicó (el médico) la posibilidad de otro examen? Respuesta: no señora. Pregunta: ¿Usted le explicó que era la tercera vez que iba del 11 al 13? Respuesta: sí señora y le comenté que hacía dos meses mi hijo había sufrido el mismo golpe. Lo único que hizo el doctor fue cambiar de Ibuprofeno a Naproxeno y me envío para hacerle unas terapias respiratorias a mi hijo. Pregunta: ¿Y que por qué terapias? Respuesta: que porque al hacerle la revisión lo había visto era malo del pechito. Pregunta: ¿Qué decía respecto a la diferencia del tamaño de los testículos? Respuesta: No, que estaba normal... Pregunta: ¿el niño podía caminar? Respuesta: No señora. Pregunta: el niño se mostraba fastidioso con el pantalón frente al médico? Respuesta: Sí señora. Pregunta: ¿El niño lloraba? Respuesta: Sí señora. Pregunta: ¿Y qué manifestó el médico? Respuesta: Que le diera, o sea que le cambiaba era el medicamento. Pregunta: ¿Qué por qué se lo cambiaba? Respuesta: Que el Naproxeno era más fuerte. Pregunta: ¿Y no refirió (el médico) la posibilidad de otro examen? Respuesta: no señora. Pregunta: ¿Qué más le dijo el médico? Respuesta: No. De ahí solamente me dijo que pues que sacara la cita que me había dado la orden el médico del hospital San José, y ya, y me dio de salida. Pregunta: ¿en algún momento de la consulta él le refirió sobre posibles complicaciones? Respuesta: No señora.

\footnotetext{
${ }^{48}$ CD 23-1, feb. 23/15, pista 2a, récord 47:47 y ss
} 
Ella cambió el medicamento, ${ }^{49}$ y al otro día a las 6 de la mañana, el día 13 de octubre, se fue para la Clínica San Rafael para la terapia respiratoria que le había ordenado el doctor HR. Llegó temprano, a las 6 de la mañana, pagó las terapias. La enviaron al sótano. La terapeuta respiratoria se le acercó. El estado de salud del niño era vejatorio: se retorcía del dolor y la madre se sentía más impotente. Entonces, la terapeuta llamó de inmediato a una cirujana pediatra, quien vino a los 10 minutos; era la doctora XD. Muy pronto descubrió esta galena la gravedad de la situación, dispuso la intervención quirúrgica inmediata, e intentó salvar el testículo, pero para entonces el testículo ya estaba muerto.

5.6.3.2. El tribunal quiere dejar en claro que no comparte la conclusión del defensor en el sentido de que el aumento del tamaño testicular del niño se había dado, en exclusiva, desde la noche anterior, de modo que el doctor $\mathrm{R}$, cuando vio al infante, no tenía por qué descubrir una torsión para entonces inexistente. Tal afirmación del letrado, con el respeto que nos merece, es parcializada y fragmenta la declaración de la madre del pequeño. Si reexaminamos el testimonio de esta mamá, sin mayor elucubración notaremos que la agravación continua de la salud del menor fue la constante en esos terribles tres días, pues el niño presentaba inflamación testicular desde el primer día.

No podemos llegar a una especie de idolatría exegética de lo que consigna una historia clínica, olvidando, por completo, lo que el paciente declara que ha sentido. La historia clínica es palabra humana, no palabra divina; es una parte de la historia del caso, pero la historia que relata el paciente, no se puede descartar sin más. Por ello, si bien respetamos el esfuerzo defensivo, estimamos que no es admisible que se quiera vender la idea de que la dolencia que el párvulo padeció desde el jueves 11, que siguió y se agravó, el viernes 12, fue algo totalmente inconexo con la cirugía que se le practicó el día sábado.

Si se nos permite la expresión, acá no tenemos el caso de un niño que comienza un día con una afección en el órgano A, y por razones repentinas o de sortilegio, resulta, al tercer día, con la afectación pero del órgano B. El tribunal, con la explicación que los expertos han hecho, no tiene problema en entender que una órgano es el epidídimo y otra la gónada, pero es que desde el punto de vista científico, con todo comedimiento hay que decir que ninguno de los expertos que aportaron sus luces en el juicio explicaron cómo es que, en el caso particular del niño DSMR, a quien le duele su inflamado testículo izquierdo por tres días seguidos, de una supuesta inexistencia de torsión, la torsión al final surge, casi que de pura casualidad, al tercer día.

Es cierto que se ha dicho que entre la torsión y la pérdida del testículo pasan entre 6 y 24 horas (eso lo entiende el tribunal), pero es que cuando el niño fue, finalmente, intervenido en la Clínica San Rafael, el testículo izquierdo ya estaba muerto, luego la pérdida se pudo haber presentado no solo horas, sino días antes. El rango que va de 6 a 24 horas, según lo informado por expertos en el juicio, es el rango para que el testículo no haga necrosis, pero no hay una regla de la ciencia que diga, que ya muerta la gónada, no se puede hacer intervención quirúrgica, tanto que eso fue lo que ocurrió con el menor DSMR. Además, siendo sinceros, nadie se ha atrevido a fundamentar el momento en que la necrosis de esta gónada se produjo.

5.6.3.3. Ahora bien; el tribunal no es experto médico para indicarle al doctor HR lo que tenía que hacer en la tarde del viernes 12, pero para determinar su conducta profesional a

${ }^{49}$ Ibídem. 50:49 y ss. 
seguir nos basamos en el dictamen de Medicina Legal que al respecto bien dijo, respecto de la necrosis que genera la torsión testicular:

El proceso ocurre rápidamente y por lo general está instaurado a las 6 horas del accidente, en la medida que transcurre el tiempo las oportunidades de que sea reversible son menores y en general a más de 24 horas de ocurrido el accidente la gónada está necrosada y perdida ${ }^{50}$.

Si la defensa hubiera querido acreditar el surgimiento de la torsión testicular entre las tres de la tarde del viernes 12, y las 6 de la mañana del sábado 13, hubiera podido traer los expertos que soportaran tal hipótesis fáctica, pero lo que no puede hacer el tribunal es tapar la evidencia que apunta a lo contrario, y olvidarse de que la dolencia padecida por el pequeño DSMR fue una sola desde el jueves 11, solo que cada vez más angustiante a medida que transcurrían esas tormentosas horas. Para que quede claro, al niño DSMR no se le inflamó el testículo (entendido como un conjunto que incluye el escroto) la noche del viernes, sino desde el jueves en la mañana.

5.6.3.4. Concordante con lo anterior, nos preguntamos: ¿Por qué razón tiene que padecer una madre dos tortuosos días resistiendo el lamento y lágrimas de su primogénito de tres años, y el tercer médico que ve al pequeño, lo único que hace es cambiar de analgésico? En Bogotá, con el amplio ramillete de opciones en materia de imágenes diagnósticas, nada de eso generó inquietud en este profesional. Si como la misma mamá del niño nos ha contado, el testículo tenía un color entre rojo y negro, si la inflamación seguía, si el dolor no paraba, ¿no tiene la ciencia médica, en la capital de Colombia, una opción distinta a recetar más analgésicos? La respuesta la tuvo la señora RB en la clínica San Rafael de esta ciudad al día siguiente. Entonces, sí existía esa otra opción. Fue en esta clínica donde se descubrió lo que ninguno de los profesionales anteriores había descubierto: una torsión testicular.

\section{Comentarios finales}

Dos comentarios para finalizar:

6.1. Un desliz que mortifica a los señores defensores tiene que ver con que el juez de primera instancia, en una redacción de poca técnica jurídica, haya hablado de coautoría. $\mathrm{Al}$ respecto hay que decir, que al menos en este momento, la coautoría imprudente no es vocablo. Veamos:

El Tribunal Superior de Bogotá confirmó el anterior proveído y aclaró en la parte motiva del mismo que sí era posible plantear una coparticipación en el delito culposo, en la medida en que el acuerdo de voluntades se predique de la acción que produjo el resultado típico y no del propósito de producirlo.

De acuerdo con lo expuesto en precedencia, lo que quería sostener el ad quem era que el riesgo jurídicamente desaprobado fue administrado por más de una persona en el presente asunto y, por lo tanto, éste les competía a los procesados. Es decir, que cada una de las acciones emprendidas por los doctores FAGT y FBB no fue suficiente para la producción del resultado típico sino que el mismo se concretó debido a la concurrencia de ambas.

\footnotetext{
${ }^{50}$ Fl. 194 ibídem.
} 
Sin embargo, dado que en el delito imprudente la ley no distingue las clases de participación ni las formas de causación del resultado típico, como también se acabó de analizar, cada uno de los procesados recibió un tratamiento uniforme a título de autor.

En este orden de ideas, no es cierto, como al parecer lo entendió el demandante, que el Tribunal construyó una coautoría impropia o funcional para el delito imprudente cometido por los procesados, e incluso, en el caso de que así lo hubiera hecho, el defensor tenía que haber sustentado las razones por las cuales esta figura no podía ser de recibo en nuestro ordenamiento jurídico, como quiera que la misma ni siquiera corresponde a un imposible dogmático según un creciente sector de la doctrina ${ }^{51}$.

6.2. En segundo y último comentario es que el tribunal, en este caso, tiene una conclusión que, sin apelar a un lenguaje pomposo, quiere expresar en los términos más sencillos posibles: la torsión que terminó con la pérdida del testículo izquierdo de un niño que por las restricciones legales no podemos llamar por su nombre, sino por sus iniciales, DSMR, no ocurrió por obra del azar. Cuando el sábado 13 de octubre, el niño fue intervenido quirúrgicamente, ya fue demasiado tarde. Para entonces, su madre había deambulado, días enteros por varias instituciones de salud donde los tres médicos encausados vieron al niño, y todos, en forma coincidente, lo devolvieron para la casa con analgésicos.

El tribunal no es un ente especializado en medicina para determinar en qué momento, entre el jueves 11 de octubre y el sábado 13, ocurrió la torsión del testículo del pequeño, pero en un caso delicado, como ese, que exigía una atención perenne, un seguimiento constante, varias omisiones tuvieron lugar: la doctora VB remitió al niño a un pediatra, pero lo remitió solo de palabra y no en forma ni escrita ni muchos menos prioritaria. El doctor FL se contentó con una ecografía tomada en la mañana por orden de la doctora V, pero sin considerar que en doce horas el estado orgánico del niño había podido cambiar; además, el doctor FL aseguró que el niño no sentía dolor, cuando es claro que fue llevado al consultorio de este, justo por el dolor que los quejidos del niño revelaban. Y finalmente, tal vez en el comportamiento más inaudito, el doctor RM no vio lo que la madre sí pudo ver: un testículo de un rojo oscuro como una ciruela.

No quiere decir, lo anterior, que los doctores acusados hayan procedido de mala fe, o con ánimo torticero o intención malvada. Por supuesto que no. Pero lo que sí nota el tribunal es que obraron con descuido, y ese descuido ha significado un error que el tribunal no puede pasar por alto. Errar es humano, pero tiene consecuencias. Hubo una violación al deber objetivo de cuidado que les era exigible, y esa omisión constituyó un riesgo, o más bien, aumentó el riesgo que ya padecía el niño con su dolencia. El riesgo así configurado se acrecentó hasta que el 13 de octubre vino a realizarse en un resultado que afectó la salud del niño DSMR. El niño perdió, para siempre, su testículo izquierdo. Tal vez si hubiera tenido la fortuna de contar con mejores médicos, la suerte de ese, la mitad de su órgano reproductor, hubiera sido distinta.

En mérito de lo expuesto, el Tribunal Superior de Bogotá, Sala Penal, administrando justicia en nombre de la República de Colombia y por autoridad que le confiere la ley,

Resuelve:

$\mathbf{1}^{\circ}$ Confirmar en su integridad la sentencia apelada.

${ }^{51}$ CSJ. Nov. 8/07 MP Socha Salamanca, e27388. 
$2^{\circ}$ Advertir que, contra esta decisión, se puede interponer, en los términos de ley, el recurso extraordinario de casación.

$3^{\circ}$. Enviar copia de esta decisión al juzgado de primera instancia

Se notifica en estrados,

Comuníquese y cúmplase,

\author{
Orlando Muñoz Neira Fernando Adolfo Pareja Reinemer \\ Hermens Darío Lara Acuña \\ Con salvamento de voto
}

\title{
Comentario
}

\section{Introducción}

El caso objeto de la decisión comentada propone diversos problemas, todos ellos de grandes importancia e interés; así ocurre, por ejemplo, con lo atinente a la coautoría en tratándose de los delitos imprudentes, la determinación de la infracción al deber objetivo de cuidado en los asuntos médicos o el papel del conocimiento privado del juez a la hora de proferir sus respectivas sentencias.

Naturalmente, las cuestiones apuntadas revisten una gran complejidad y no pueden ser objeto de un examen detallado en un comentario como el que sigue, por eso, es importante aclarar, primero, que las líneas ulteriores se concentran en el último de los tópicos mencionados y, segundo, que tal decisión se debe, además de las razones de espacio connaturales a este tipo de ejercicios académicos, a la falta de interés que, en términos generales, dicho tema ha suscitado entre los autores especializados -no sólo nacionales-. Se trata, por consiguiente, de proponer algunas reflexiones en torno a un tema de particular relevancia que, por diversas razones y pese a su evidente trascendencia, no ha despertado mayor interés en Colombia.

En efecto, lo relativo al conocimiento privado del juez y la prohibición de utilizar tal información como fundamento de las decisiones judiciales, es un tema que apenas ha tratado la jurisprudencia colombiana y que nuestros autores han olvidado casi por completo. $\mathrm{Y}$, aunque es cierto que numerosas providencias e instrumentos internacionales tocan asuntos estrechamente ligados con el asunto, tales como los principios de necesidad de la prueba, la imparcialidad del juzgador, el derecho de defensa o el principio acusatorio, entre otros, la verdad es que son pocas las referencias explícitas o directas a la cuestión propuesta.

En orden a contextualizar -rápidamente- el tema elegido, puede decirse que la máxima expresión del poder punitivo es la imposición de sanciones penales mediante una sentencia condenatoria y esta última, acorde con el sistema legal actual y en virtud del principio de necesidad de la prueba (num. 4, art. 164 CPP), cuyo fundamento es tanto jurídico como político (Vargas, 2010, p. 139), debe estar afincada en las pruebas debidamente allegadas e incorporadas al proceso. Esto, 
pues se entiende que sólo a través de aquellas el juez puede alcanzar el nivel de conocimiento necesario para tomar su decisión (arts. 372 y 381 CPP).

Al hilo de lo anterior, es importante añadir que los principios acusatorio y de imparcialidad limitan las actividades investigativa y probatoria del juez, de tal forma que le está vedado emprender tareas propias de las partes como las de investigar o procurar, por su propia iniciativa, elementos probatorios sobre el caso, a fin de obtener el conocimiento requerido para decidir (Caferrata, 2000, p. 31). En este punto, habría que citar, así mismo, ciertos postulados o axiomas que complementan el marco al que viene de hacerse referencia, cuales son el principio de igualdad, el in dubio pro reo, el derecho de defensa o, en fin, la prohibición de decretar pruebas de oficio.

Lo anterior, considerado en su conjunto, constituye -a grandes rasgos- la razón de ser de la prohibición de la utilización del conocimiento privado del juez, pero en forma alguna contribuye a definir la noción de 'conocimiento privado'. En tal virtud, las páginas siguientes se ocupan de precisar su contenido, límites y fines, puesto que se trata, en definitiva, de responder a la pregunta de si el juez de primera instancia se valió de un conocimiento privado cuando concluyó que los médicos violaron el deber objetivo de cuidado al pretermitir un tratamiento quirúrgico inmediato para un caso de escroto agudo, conforme lo sugiere el protocolo mexicano IMSS 229-10, en tanto dicho protocolo no fue llevado al juicio por la acusación o la defensa sino que fue conocido por el fallador gracias a su investigación personal.

En este orden de cosas, el presente comentario se propone, en primer lugar, definir la noción de conocimiento privado y, para ello, se examinan los aportes doctrinales sobre el particular y las sentencias de la Corte Suprema de Justicia que han tratado la cuestión. En segundo lugar, teniendo como referente los presupuestos anotados, se brinda una respuesta al interrogante formulado y se consignan unas reflexiones finales sobre el mismo punto de cara al ordenamiento colombiano.

\section{Apuntes doctrinales sobre el conocimiento privado del juez}

El tema elegido presenta un primer problema: delimitar el 'saber oficial', que es el aceptado a los efectos de la motivación de la decisión del juez, del llamado 'conocimiento privado', que, como ya se afirmó, está prohibido por mandato legal. Esta diferenciación no es sencilla, pues en la psiquis del juez ambas formas de conocimiento van y vienen sin dividirse y sin que resulte fácil distinguirlas de una forma objetiva (Stein, 1999, p. 99).

Pese a lo anterior, puede intentarse diferenciarlas a partir de la forma en que el juez adquirió dicho saber (Stein, 1999, p. 99) y, a tono con este criterio, el conocimiento oficial es aquel que se le ha trasmitido al juzgador por los medios de prueba incorporados al proceso con el cumplimiento de las formalidades propias de cada caso y sin afectar derechos fundamentales. Por su parte, el conocimiento 
privado se define de forma negativa e incluye todo aquel conocimiento que no cumple -en principio- con estas características; sin embargo, la fórmula enunciada no es absoluta, pues obliga a distinguir, prima facie, el conocimiento privado del juez de algunas figuras semejantes, por lo menos en apariencia, como son las máximas de la experiencia, los hechos notorios y el conocimiento de la normatividad o de la jurisprudencia, por mencionar las más relevantes.

Otra vía para delimitar el concepto en estudio surge de examinar el principio de la prohibición del conocimiento privado del juez, pues dicho postulado limita el convencimiento del juez a los medios de prueba (Devis, 1994, p. 110), de tal forma que los hechos sobre los cuales se funde la decisión judicial deben estar demostrados por pruebas aportadas al proceso por cualquiera de las partes o por el juez, siempre que el mismo tenga facultades expresas para ello, como en el modelo inquisitivo. En cualquier caso, las pruebas no pueden ser suplidas por el conocimiento personal o privado que el juzgador tenga sobre los hechos $\mathrm{y}$, obvio es decirlo, ello cobra más fuerza en el marco de un proceso penal de tendencia acusatoria, como el vigente en Colombia.

El origen del principio examinado se asocia a los diferentes modelos de valoración probatoria: para algunos, este principio prohibitivo nace en el seno del sistema de tarifa legal, señalando, incluso, que se trata de una tarifa legal negativa; otros, en cambio, rechazan lo anterior y afirman que, aun en los sistemas de libre valoración o de íntima formación de la convicción, no es posible acudir al conocimiento privado del juez, pues en todos ellos la máxima aludida se erige como una garantía de primer orden, cuya finalidad es la de evitar la vulneración de los principios de publicidad y contradicción, verdaderas columnas vertebrales dentro de un proceso constitucional respetuoso de los derechos fundamentales de las partes. Desatender este precepto colocaría a las partes frente a un juez parcial (Devis, 1994, p. 114).

Este principio es, además, reconocido desde diferentes visiones -inclusive antagónicas- del derecho (Devis, 1994, p. 114); así, por ejemplo, J. Bentham rechazó dar cualquier valor probatorio al conocimiento privado del juez al considerar que no basta que la decisión sea justa sino que es necesario, además, que lo parezca (Bentham, 1825, p. 123) o E. Florián, quien también se muestra en contra de tal forma de conocimiento, pero porque considera, a tono con la filosofía positivista, que lo que no existe en el proceso no existe en el mundo (Devis, 1994, p. 114).

\section{El conocimiento privado del juez en la jurisprudencia de la Corte Suprema de Justicia.}

En lo que respecta al tratamiento del asunto por parte de la jurisprudencia nacional, es necesario enmarcar la discusión en el ámbito de la causal de casación conocida como falso juicio de existencia, pues es allí donde se estudia por parte de la Corte. 
Así, en 2004, la Corporación estudió una demanda de casación interpuesta en un proceso por homicidio agravado y porte ilegal de armas; en su escrito, el accionante cuestionó el proceder del Tribunal Superior que tuvo en cuenta la constatación realizada por una de sus magistradas quien se dirigió personalmente al lugar de los hechos, lo cual le permitió concluir, con base en su percepción, que no existían vías de escape y que, por ello, el aprehendido debía ser uno de los atacantes y no un simple transeúnte (Corte Suprema de Justicia, sentencia No. 17.855, 2004).

En este caso, la Corte consideró que el Tribunal tomó como prueba "el conocimiento que en forma unilateral y por fuera del procesamiento adquirió la magistrada ponente, como de ello dio cuenta en la decisión" (Corte Suprema de Justicia, sentencia No. 17.855, 2004); no obstante lo anterior, también señaló que los efectos nocivos de esta clase de error están atados a su capacidad "para servir de prueba exclusiva del hecho o para reemplazar la prueba del mismo que ha sido aportada" (Corte Suprema de Justicia, sentencia No. 17.855, 2004). Por lo tanto, como consideró que en el proceso entonces en estudio obraban pruebas suficientes para determinar la responsabilidad penal del procesado, pese a reconocer el error de hecho, optó por no casar la sentencia impugnada.

El siguiente antecedente importante sobre la materia se encuentra en el Auto del seis (06) de mayo del mismo año (Corte Suprema de Justicia, Auto No. 15.754 de 2006) -citado en numerosas ocasiones por el máximo tribunal en lo penal-, mediante el cual fue inadmitida una demanda de casación. En dicha ocasión, la Sala indicó que el denominado error de hecho por falso juicio de existencia solo puede darse en una de dos formas: por omisión, es decir, porque el juez ignoró una prueba que obraba dentro del proceso, o por suposición, cuando el funcionario incluyó en las consideraciones una prueba que nunca fue debidamente incorporada; en este último supuesto se encuadra el fenómeno del conocimiento privado del juez.

Así mismo, afirma que este error de hecho 'tiene una naturaleza puramente objetiva al ocurrir en el plano lógico de la aprehensión material de la prueba durante el proceso de construcción de la sentencia' y añade, en orden a precisar los requisitos para la formulación del cargo, que:

Una censura de violación indirecta de la ley por falso juicio de existencia en la forma de suposición de prueba, que pretenda ser estimada como correctamente enunciada y adecuadamente fundamentada, debe partir de la identificación exacta de cuáles fueron las pruebas en que se fundó la decisión. Una vez realizado ese ejercicio, debe distinguir de manera clara y precisa, si entre esas pruebas existe alguna que haya sido objeto de suposición por parte de los Juzgadores, en caso positivo, debe identificarla y demostrar cuál fue exactamente su incidencia en la construcción del fallo atacado [...] (Corte Suprema de Justicia, Auto No. 15.754 de 2006).

El 21 de julio de la misma anualidad, al estudiar de un caso de usurpación de marcas y patentes, la Corte (Sentencia No. 19.702 de 2004) revisó nuevamente el tema del conocimiento privado del juez que profirió sentencia condenatoria sin que se hubiera allegado al proceso el registro de la marca en cuestión; ello, en 
opinión del recurrente, implicaba que no se había probado el elemento normativo objetivo del tipo de usurpación de marcas y patentes consistente en la calidad de 'protegida legalmente'. En aquella ocasión, la Corte encontró probada la causal alegada y casó la sentencia.

Luego, en sentencia de dos de septiembre de 2009, al referirse al principio de necesidad de la prueba, la Corporación apuntó que:

De manera insalvable los actos y providencias que se profieran al interior del debido proceso penal en sus etapas de investigación y juzgamiento, necesariamente deben estar fundados en soportes que obedezcan a existencia material y desde luego jurídica, y en esa medida no pueden llegar a ser objeto de suposiciones ni de omisiones, ni suplirse a través de conjeturas, ni por el conocimiento privado del juez [...] (Corte Suprema de Justicia, Sentencia No. 29.221 de 2009).

De igual forma, resaltó que:

El conocimiento privado del juez o de los demás sujetos procesales no tiene efectos probatorios. El juez no puede ostentar simultáneamente con su labor juzgadora la calidad de testigo. La decisión judicial sólo puede pronunciarse sobre lo probado en el curso de la actuación. La evaluación de pruebas inexistentes vulnera este principio y constituye una irregularidad sustancial generadora de nulidad (artículo 457 inciso $1^{\circ}$.). El falso juicio de existencia al valorar la prueba viola este principio y da lugar a casación (art. 181 numeral. $3^{\circ}$ ). Este principio está íntimamente ligado al de legalidad. Cumple con la necesidad, la prueba practicada legalmente o de manera regular, esto es, por el sujeto competente, cuando su objeto es pertinente, el procedimiento o rito de su aducción es el previsto en la ley y la valoración se produce libremente [...] (Corte Suprema de Justicia, Sentencia No. 29.221 de 2009).

En esta revisión de la jurisprudencia más relevante, es necesario mencionar el salvamento de voto del magistrado Bustos Ramírez a la sentencia de once (11) de abril de 2012, en la cual se analizó la absolución de un médico cirujano por el delito de lesiones personales culposas. En esa decisión, según el magistrado que salvó el voto, la Corte sorprendió a la defensa al dejar de lado los precisos términos de la acusación, abandonar el contenido de la pericia científica y acudir a las manifestaciones de legos en la materia, con base en documentos de apariencia científica que no fueron materia de controversia durante la investigación o el juzgamiento. Como resultado de lo anterior, la Corporación afirmó que el yerro del galeno se presentó en el procedimiento quirúrgico y que dicho desacierto causó las lesiones en la paciente.

Agrega que su mayor preocupación radica en que, a su modo de ver:

A partir de ahora va a generarse de manera equivocada, por ende nociva para la funcionalidad del modelo de procesamiento penal, en el sentido que los jueces se hallan facultados por el ordenamiento para prescindir de la pericia científica y realizar sus propias averiguaciones sobre el estado de la ciencia de cuyo conocimiento de ordinario carecen y, a partir de allí, supliendo a los doctos en la materia, expresar particulares criterios sobre un caso concreto, a la mejor manera de aquello que se ha 
convenido en denominar "el conocimiento privado de juez" [...] (Corte Suprema de Justicia, Sentencia No. 33.920 de 2012).

Y, a renglón seguido, apunta:

Por ello llama la atención que en la decisión se afirme que el médico procesado ha debido realizar la cirugía de tal o cual modo, o aplicar determinados procedimientos, o recetar un específico medicamento porque así aparece en alguna literatura consultada a propósito de la decisión, sin posibilidad alguna de permitir la controversia de las partes, pues no puede olvidarse que aún en el caso del dictamen pericial, la ley les confiere la oportunidad de pedir aclaración o incluso de presentar objeción por error grave u ostensible [...] (Corte Suprema de Justicia, Sentencia No. 33.920 de 2012).

En una decisión posterior, bajo el radicado 34867, indica la Corte que: "la prohibición a la que alude la norma (artículo 435) se vincula con el conocimiento personal de los hechos investigados, no con la aplicación de principios o teorías científicas, de aceptación universal, de los cuales se tiene conocimiento" (Corte Suprema de Justicia, Auto No. 34867 de 2012).

Finalmente, ya en el año 2013, la Sala consideró que la motivación de un juez de primera instancia para condenar con base en la percepción que tuvo de la forma de caminar del acusado al ingresar y abandonar la sala de audiencias, que correspondía con la descripción de un testigo constituía "una suerte de conocimiento privado del fallador, que le hace adquirir la condición excluyente de testigo y juez en el mismo proceso" (Corte Suprema de Justicia, Sentencia No. 36.518 de 2013).

\section{El concepto de 'conocimiento privado' y la justificación de su utilización.}

Con base en lo anterior, es posible aproximarse al concepto 'conocimiento privado' del juez, definiéndolo y caracterizándolo, a partir de los diferentes elementos aportados tanto por la doctrina como por la Corte, al tiempo que se exponen las consecuencias de su aplicación al caso examinado en la sentencia objeto del presente comentario.

En primer lugar, doctrina y jurisprudencia coinciden en que el objeto del conocimiento privado del juez son los hechos; de tal forma que se puede considerar como privado todo aquel conocimiento del juez referido a los hechos objeto de discusión en el proceso, no así el que se posee sobre teorías, técnicas, máximas de la experiencia, entre otros, pues los mencionados, aunque sean información conocida por el juez de modo exclusivo, no constituyen hechos en sí mismos sino medios para valorar estos últimos.

En segundo lugar, es importante advertir que el conocimiento susceptible de catalogarse como privado es el obtenido por el juez a través de ciertos medios; así, se considera que hacen parte del conocimiento privado del juez todos los datos relativos a la existencia de los hechos aprehendidos por el funcionario gracias a medios distintos a los probatorios debidamente decretados y practicados en el marco del proceso penal correspondiente. 
En tercer lugar, este tipo conocimiento debe ser utilizado para motivar la decisión, pues lo reprochable no es el hecho de poseerlo sino, más bien, el de utilizarlo a la hora de fundamentar la sentencia; en tal sentido, el art. $435 \mathrm{CPP}$, en su inciso segundo, dispone que 'en ningún caso el juez podrá utilizar su conocimiento privado para la adopción de la sentencia a que hubiere lugar'. Se trata, entonces, de un conocimiento que versa sobre los hechos objeto del proceso que no fue obtenido mediante los medios probatorios debidamente decretados y practicados y que sirve de sustento a la decisión del juez.

Puesto en clave de lo que podría ser su desarrollo jurisprudencial como causal de casación, debería añadirse una condición más: dicho conocimiento ha de ser determinante para la decisión adoptada; esto, naturalmente, habrá de examinarse en cada caso y teniendo a la vista el material probatorio existente.

Ahora bien, aunque no puede negarse que existen otros conceptos capaces de generar algún tipo de confusión a la hora de deslindarlos del 'conocimiento privado' del juez, como ocurre con los hechos que no requieren de prueba o las máximas de la experiencia, lo cierto es que la delimitación es posible si se atienden los criterios expuestos con antelación.

En otro orden de cosas, y esclarecidas las pautas que permiten precisar cuándo se está frente a un conocimiento privado del juez, corresponde indicar las razones por las cuales conviene prohibir su uso: por una parte, su interdicción protege el debido proceso en tanto garantiza los principios de publicidad y de contradicción; actualmente, resulta inaceptable un modelo de proceso penal que permita recurrir a motivaciones subterráneas, alejadas de las condiciones que propicia el debate probatorio. En este sentido, propende por la armonía del sistema de valoración de las pruebas, posibilitando la discusión y la participación de las partes e intervinientes que emplean los distintos medios probatorios para controvertir los hechos.

Por la otra, se preserva el principio del juez imparcial y, en este sentido, se mantiene la integridad del sistema/principio acusatorio, pues si el juez acude a su conocimiento privado o, peor aún, si se convierte él mismo en investigador de los hechos, se transforma en una parte.

\section{La sentencia comentada y el conocimiento privado del juez.}

La conducta del juez que, a espaldas de las partes, después de concluida la controversia probatoria y surtida la vista pública, ingresa a un buscador web donde encuentra un protocolo mexicano con base en el cual, durante la audiencia de lectura del fallo, precisa el deber objetivo de cuidado que le cabía a los investigados, es, sin lugar a dudas, un caso que hace evidente el uso de un conocimiento privado.

En efecto, el juez de la primera instancia declaró conocer un hecho relevante para el proceso, cual fue el procedimiento 'adecuado' para el tratamiento del caso de escroto agudo (hechos). 
Dicho conocimiento sobre el procedimiento lo obtuvo de un documento al cual tuvo acceso mediante una búsqueda en internet realizada por él mismo, no a partir de las pruebas debidamente decretadas y practicadas, privando a las partes de la posibilidad de debatir sobre el protocolo mismo o sus contenidos (medios).

A partir de la constatación de la referida infracción al deber objetivo de cuidado, fundamentó la responsabilidad de los procesados en la modalidad culposa (uso) y, además, el mismo juez indicó expresamente que las pruebas practicadas en el juicio no permitían derivar la responsabilidad penal y que, por ello, la referencia al protocolo derivaba fundamental (determinante).

En este sentido, no puede estarse de acuerdo con la segunda instancia cuando le restó importancia a que el juez a quo hubiera hecho uso de un conocimiento privado, llegando incluso a negar que ello hubiera ocurrido, al margen de que finalmente considerara que en la actuación sí obraban pruebas suficientes para endilgar responsabilidad a los médicos condenados. Atendidos los criterios expuestos en precedencia, parece innegable que, efectivamente, el juez a quo acudió a su conocimiento privado para fundamentar la sentencia condenatoria.

Por último, preocupa el lenguaje un tanto agresivo y condescendiente con el que se refieren en la sentencia los argumentos de los recurrentes y la forma apresurada en la que se despachan los mismos, pues ese, en nuestro parecer, no es un actuar consecuente con la función desempeñada por quien tiene la importante misión de administrar justicia y colma de emociones no deseadas un espacio que, deontológicamente, pertenece al campo de la argumentación jurídica y nada más.

Bogotá, febrero de 2016.

\section{Referencias}

Auto 34.867 (2012, junio 27). Casación. M.P. José Leonidas Bustos Martínez. Sala de Casación Penal, Corte Suprema de Justicia.

Auto 15.754 (2004, mayo 6). Casación. M.P. Yesid Ramírez Bastidas. Sala de Casación Penal, Corte Suprema de Justicia.

Bentham, J. (1825). Tratado de las pruebas judiciales. París: Bossange Frères.

Cafferata, J. (2000). Proceso penal y derechos humanos. Buenos Aires: Editores del Puerto S.L.R.

Calamandrei, P. (1973). Derecho procesal Civil (Vol. I). Buenos Aires: Ediciones Jurídicas Europa América.

Canosa, U. (1999). Derecho probatorio disciplinario. Bogotá: Procuraduría general de la nación.

Carnelutti, F. (2007). Cómo se hace un proceso. Bogotá: Temis. 
Dellepiane, A. (2003). Nueva Teoría de la Prueba. Bogotá: Temis.

Devis, H. (1994). Compendio de Derecho Procesal, Pruebas Judiciales, (Tomo II). Bogotá: Biblioteca Jurídica Dike.

Fierro, E. (2010). La prueba ilícita e ilegal efectos jurídicos en el proceso penal. Bogotá: Leyera.

Parra, J. (2009). Manual de Derecho Probatorio. Bogotá: Ediciones Librería del Profesional.

Sentencia 17.855 (2004, febrero 18). Casación. M.P. Alfredo Gómez Quintero. Sala de Casación Penal, Corte Suprema de Justicia.

Sentencia 19.702 (2004, julio 21). Casación. M.P. Alfredo Gómez Quintero. Sala de Casación Penal, Corte Suprema de Justicia.

Sentencia 29.221 (2009, septiembre 2). Casación. M.P. Yesid Ramírez Bastidas. Sala de Casación Penal, Corte Suprema de Justicia.

Sentencia 31.197 (2009, marzo 26). Casación. M.P. María del Rosario González. Sala de Casación Penal, Corte Suprema de Justicia.

Sentencia 33.920 (2012, abril 11). Casación. M.P. Augusto J. Ibáñez Guzmán. Sala de Casación Penal, Corte Suprema de Justicia.

Sentencia 36.518 (2013, octubre 9). Casación. M.P. José Leonidas Bustos Ramírez. Sala de Casación Penal, Corte Suprema de Justicia.

Stein, F. (1988). El conocimiento privado del juez. Bogotá: Temis.

Vargas, Á. (2010). El trasfondo jurídico-político del deber de motivar que pesa sobre el juez en el sistema acusatorio. En F. Velásquez (Coomp). Sistema Penal Acusatorio y Nuevos Retos. Colección Estudios de Derecho (pp. 139-178). Bogotá: Universidad Sergio Arboleda. 